\title{
A comparative study of dragonfly inspired flapping wings actuated by single crystal piezoceramic
}

\author{
Sujoy Mukherjee ${ }^{1}$ and Ranjan Ganguli $i^{*}$ \\ Department of Aerospace Engineering, Indian Institute of Science, Bangalore-560012, \\ India
}

\begin{abstract}
A dragonfly inspired flapping wing is investigated in this paper. The flapping wing is actuated from the root by a PZT-5H and PZN-7\% PT single crystal unimorph in the piezofan configuration. The non-linear governing equations of motion of the smart flapping wing are obtained using the Hamilton's principle. These equations are then discretized using the Galerkin method and solved using the method of multiple scales. Dynamic characteristics of smart flapping wings having the same size as the actual wings of three different dragonfly species Aeshna Multicolor, Anax Parthenope Julius and Sympetrum Frequens are analyzed using numerical simulations. An unsteady aerodynamic model is used to obtain the aerodynamic forces. Finally, a comparative study of performances of three piezoelectrically actuated flapping wings is performed. The numerical results in this paper show that use of PZN-7\%PT single crystal piezoceramic can lead to considerable amount of wing weight reduction and increase of lift and thrust force compared to PZT-5H material. It is also shown that dragonfly inspired smart flapping wings actuated by single crystal piezoceramic are a viable contender for insect scale flapping wing micro air vehicles.
\end{abstract}

Keywords: Piezofan; single-crystal; non-linear vibrations; smart materials; aerodynamics; dragonfly; flapping; micro air vehicles.

\section{Introduction}

Research interest in flapping flight has accelerated due to the need to develop a class of very small flight vehicles called micro air vehicles (MAVs). MAVs have a large number of potential applications ranging from civil search-and-rescue missions to military surveillance missions. In order to perform these tasks, MAVs should be able to fly slowly, maneuver with a high degree of precision and navigate through complex environments. Nature provides flapping flyers such as birds and insects which routinely exhibit such performance (Ganguli et al. 2010). These natural flapping flyers represent biomimetic design for intelligent MAVs with much superior performance relative to conventional wings and rotors (Ansari et al. 2006). Hence, birds and insects are available as a natural source of inspiration for the development of MAVs. Flapping wings design for MAV represents one of the major challenges to efficient flight in the low Reynoldsnumber regime as the wings are not only responsible for lift, but also for propulsion and maneuvers (Rosenfeld and Wereley 2009).

\footnotetext{
${ }^{1}$ PhD Student, E-mail: sujoy@aero.iisc.ernet.in

$2^{2 *}$ Professor, Corresponding Author, E-mail: ganguli@aero.iisc.ernet.in
} 
To mimic the wing movement of the natural flapping flyers, several biomimetic flapping wing mechanisms were developed. Researchers have developed flapping wing mechanisms to capture bird's wingbeat kinematics. Two electrodynamic linear shaker actuators were used, by Raney and Slominski (2004), to approximately match the wingbeat patterns of hummingbirds. Their avian flapping system consisted of a 3-degree of freedom ball-and-socket connection between a fixed rigid test stand and a rigid beam element. McIntosh et al. (2006) developed a flapping mechanism for biaxial rotation of an ornithopter wing using a single actuator and spring-loaded cam-follower system. The mechanism, driven by a small DC motor, was designed to capture the wing motion of the hummingbird and hovering insects. Feathering motion was generated by a cam-follower system and flapping motion of the wing was generated by a simple four-bar mechanism. Issac and Agrawal (2007) investigated the effect of using springs and wing motions to minimize the power required by a pigeon-like mechanical bird to fly. The wing was connected to the body using two revolute joints in series. The proximal revolute joint was used for flapping and the distal joint was used to generate feathering motion. Yang et al. (2009) developed flapping wing micro air vehicles named 'Eagle II' and 'Golden Snitch'. Flapping motion of the wing was generated using the four-bar linkage transmission mechanism. Aluminum-alloy 7075 was chosen as the main structural material and electrical-discharge wire cutting (EDWC) technique was chosen to construct the gear transmission module which was driven by a commercial polylithium battery powered motor.

Several flapping wing mechanisms were developed to mimic the insect's wingbeat kinematics. To mimic the complex movements of the wings of a hovering hawkmoth, VandenBerg and Ellington (1997) made a scaled up robotic insect (the 'flapper'). In another study, Dickinson, Lehmann and Sane (1999) built a dynamically scaled model of the fruit fly, Drosophila melanogaster. Yamamoto and Isogai (2005) developed a mechanical flapping wing apparatus that dynamically simulates the tandem wing configuration of a dragonfly in hovering flight. The flapping and feathering motion were induced by electric sliders and stepping motors, respectively. In order to study the aeroelastic effects associated with the lightweight and highly flexible wing, Singh and Chopra (2008) developed an insect based flapping mechanism. They found that the thrust generating capability of MAV scale flapping wings is highly depended on wing flexibility. Recently, Nguyen et al. (2010) designed and fabricated a prototype of a flapping-wing device that can mimic some characteristics of the beetle Allomyrina dichotoma. In the design, they used a combination of a Scotch yoke and a linkage mechanism to transform the rotary motion of the motor into a large output flapping angle. Passive wing rotation was incorporated into the flapping-wing system by means of a flexible member. It can be noticed form the above studies that these dynamically scaled flapping wing mechanisms are bulky and flap at very low frequency. Moreover, current flapping wing mechanisms rely on pneumatic and motor-driven flapping actuators which lead to high weight and system-complexity (Syaifuddin et al. 2006). Additionally, it may not be easy to mimic the complex wingbeat kinematics of the natural flyers with these conventional actuators. Use of actuators made of smart materials to design flapping wing mechanism may be a plausible alternative. 
Smart materials, such as piezoelectric materials, shape memory alloys, magneto rheological fluid etc., are being considered for various engineering applications. Piezoelectric materials have been widely used as sensory and active materials in many applications in the area of adaptive structures because they have several attractive features such as high bandwidth, high output force, compact size and high power density (Chopra 2002, Zehetner and Irschik 2008). Several researchers have used piezoelectric actuators to develop biomimetic flapping wing mechanisms (Cox et al. 2002, Sitti 2003). Syaifuddin et al. (2006) have introduced a flapping wing mechanism actuated by a unimorph piezoceramic actuator, LIPCA (lightweight piezo-composite actuator). In the flapping system, the limited actuation displacement produced by bending motion of the simply supported actuator was transformed into a large flapping angle by using a four-bar linkage system. A passive wing rotation mechanism was also implemented in the flapping system. In a further study, Nguyen et al. (2008) introduced an insect-mimicking flapping-wing system actuated by unimorph piezoceramic actuator LIPCA, where the rotation, corrugation, and clapping of insect wings were mimicked. Kim et al. (2008) developed a smart flapping wing with a macro-fiber composite (MFC) as a surface actuator to generate the camber motion of a local wing section. The flapping motion was generated using an electric DC motor and a transmission system with a reduction gear system that converts the rotary motion of the motor into the flapping motion. The twisting motion was induced passively by the flexibility of the wing during up and down strokes. In another study, Kim et al. (2009) developed a biomimetic flexible flapping wing of a real ornithopter scale by using macro-fiber composite (MFC) actuators. They performed aerodynamic tests in a low-speed wind tunnel to investigate the aerodynamic characteristics, particularly the camber effect, the chordwise flexibility effect and the unsteady effect.

Most research on flapping wing mechanisms were developed using conventional PZT ceramics. Single crystals piezoceramic are the potential new generation materials being proposed in many engineering applications as sensors and actuators (Sitti 2003, Thakkar and Ganguli 2006a, $)$. Recently, lead-zinc-niobate-lead-titanate, $\mathrm{Pb}\left(\mathrm{Zn}_{1 / 3} \mathrm{Nb}_{2 / 3}\right) \mathrm{O}_{3}-\mathrm{PbTiO}_{3}$ (PZN-PT) have attracted considerable attention due to superior electromechanical properties (Thakkar and Ganguli 2006b, Pawar and Jung, 2008). Specifically, piezoelectric properties of PZN-PT type single crystals with $\left(\begin{array}{lll}0 & 0 & 1\end{array}\right)$ orientation have been found to possess large direct piezoelectric coefficients $\left(d_{33}, d_{31}\right)$ than soft piezoceramic like PZT-5H. Material properties of PZN-PT single crystals varies with the amount $(\%)$ of PT present in the piezoceramic. PZN-7\%PT has the PT composition slightly away from the morphotropic phase boundary composition and remains in the rhombohedral phase at room temperature. So, its electromechanical capacity is higher and materials properties fluctuation is much smaller compared to other varieties of PZN-PT single crystal systems. Therefore, PZN-7\%PT single crystal is one of the most suitable piezoceramics for engineering applications (Zhang et al. 2002).

Unfortunately, the piezoelectric effect is intrinsically small and leads to a small deflection when expected directly from the bending piezoelectric unimorph/bimorph (Syaifuddin et al. 2006, Chung et al. 2009). Therefore, some kind of motion amplification mechanisms 
is necessary in order to obtain large deflection. Piezoelectric fan (piezofan) is one of the simple motion amplification mechanisms. The concept of the piezofan was first proposed by Toda and Osaka (1979). Piezofan has potential usages in cooling applications in modern portable electronics such as laptops, cellular phones, automobile multimedia boxes etc. (Yao and Uchino 2001, Wait et al. 2007). Pizofan was also used in flapping wing applications by several researchers. Chung et al. (2008) used two coupled piezofans in their experiments and showed that the bending amplitude of the wing reduced with the increasing phase delay and the twisting movement increased with an increasing phase delay. In another study, selection of the best piezofans for flapping wing MAV applications based on design optimization was proposed by Chung et al. (2009). They used using the Strouhal number and a limited numbers of material parameters for the optimization. These studies used a linear analytical model to analyze the performance of piezofan structure at dynamic operation. It is clear from the flight of the natural flyers that they move their wings through a large angle. Therefore, linear model is inadequate to capture and analyze the large wing movement which can be obtained using piezofan through large deflection. Therefore, non-linear dynamic model is needed to perform dynamic analysis (Mukherjee and Ganguli 2010). Mahmoodi and Jalili (2007) derived the non-linear equations of motion of a non-homogenous piezoelectrically actuated microcantilever beam. The non-linear terms appeared in the form of quadratic expression due to presence of piezoelectric layer, and cubic form due to geometrical non-linearities. In addition to these structural aspects, aerodynamic model is needed to to consider the piezofan for flapping wing applications

Aerodynamic analysis of flapping wing is mainly performed with quasi-steady models and unsteady models (Betteridge and Archer 1974, Rayner 1979, Philps, East and Pratt 1981, Norberg 1985). Numerical simulation of flapping flight using computational fluid dynamics (CFD) was performed by several researchers (Roget et al. 2009, Chandar and Damodaran 2010). However, CFD simulations are computationally intensive and often not suitable for preliminary design studies. DeLaurier (1993) proposed an unsteady aerodynamic model which can be used to estimate the aerodynamic performances of harmonically flapping wings in the phase of preliminary design and development (Ke et al. 2008). This model is based on modified strip theory and is useful for estimating the lift generated by a flapping wing.

In this paper, an energy method is used in order to derive the non-linear equations of motion of a smart flapping wing. The flapping wing is actuated from the root by a PZT$5 \mathrm{H}$ and $\mathrm{PZN}-7 \% \mathrm{PT}$ single crystal unimorph in the piezofan configuration. Insects, such as the dragonfly, are very efficient flyers and its flight satisfies the entire flight envelope required for an MAV. Dragonflies are one of only a few species of insects that are capable of gliding flight and they are among the largest of the flying insects. Flight mechanics of different dragonfly species have been studied extensively by many researchers (Bao et al. 2006, Kim et al. 2009, Zhang and Lu 2009). The different dragonfly species provide different biomimetic designs for a flapping wing which can lead to the discovery of better configurations for engineering use. Therefore, dragonfly characteristics can provide design guidelines for the development of flapping wing MAVs. Dynamic characteristics of piezoelectrically actuated flapping wings, having the 
same size as to the actual wings of three different dragonfly species, are analyzed using numerical simulations. An unsteady aerodynamic model is used to obtain the aerodynamic forces. Finally, a comparative study of performances of three piezoelectrically actuated flapping wings is performed.

\section{Structural Model}

In this study, a piezoelectric unimorph is attached to the uniform flexible wing in piezofan configuration. The schematic diagram of the flapping wing actuated by supplying a voltage, $P_{e}(t)$ is shown in Fig. 1.

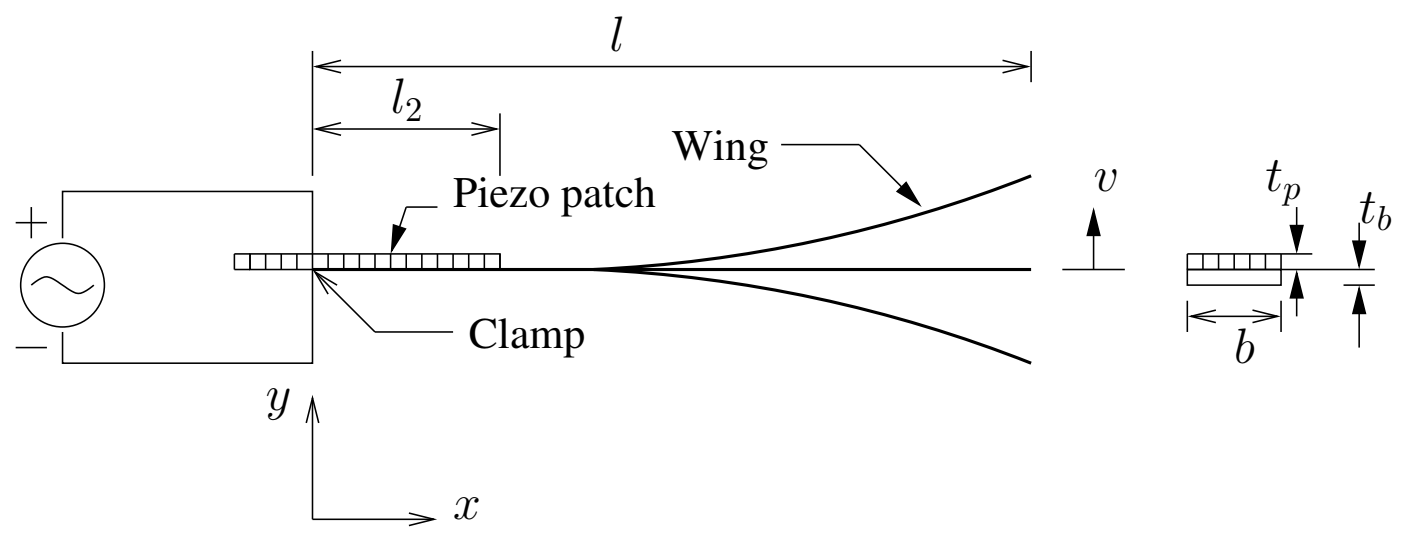

Fig. 1 Schematic of the piezoelectrically actuated flapping wing

To describe the dynamics of the wing, two coordinate systems are utilized: the $(x, y, z)$ system is considered to be inertial and the $(\xi, \tilde{\theta}, \zeta)$ system is the local principal system (Mahmoodi and Jalili, 2007). Schematic diagram of the wing geometry used for the structural modeling is shown in Fig. 2(a). Fig. 2(b) shows a wing segment of length $s$.

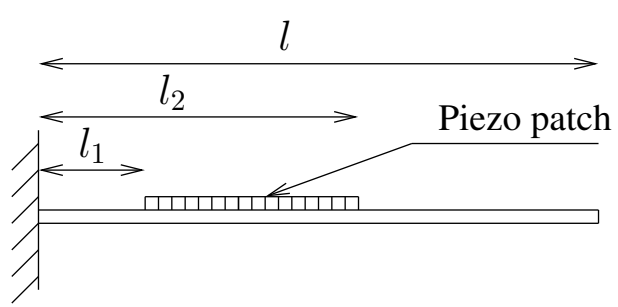

(a)

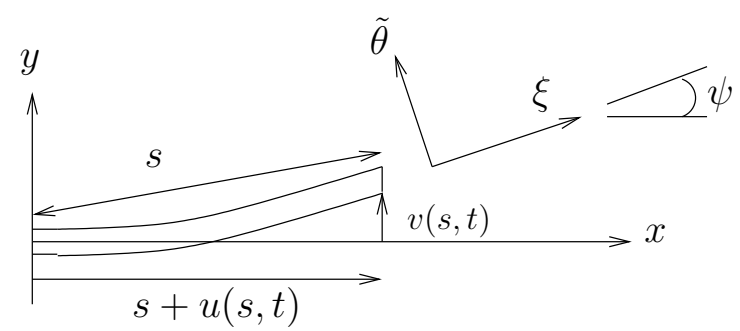

(b)

Fig. 2 (a) Schematic diagram of flapping wing geometry used for modeling, and (b)

Principal and inertial coordinate systems 
The Euler rotation, $\psi(s, t)$, represents the relationship between the principal and the inertial coordinates. Using Fig. 2(b), angle $\psi(s, t)$ for an element of length $d s$ can be written as

$$
\psi=\tan ^{-1} \frac{v^{\prime}}{1+u^{\prime}}
$$

where the over prime denotes derivative with respect to the arc length. The longitudinal and transverse displacements are described by $u(s, t)$ and $v(s, t)$, respectively. Utilizing Green's strain theory, strain of the neutral axis $\left(\varepsilon_{0}\right)$ is given by (Hsieh, Shaw and Pierre 1994)

$$
\varepsilon_{0}=\sqrt{\left(1+u^{\prime 2}\right)+v^{\prime 2}}-1
$$

Inextensibility condition can be used to relate longitudinal and bending vibration as it demands no relative elongation of the neutral axis. Using the Taylor series expansion, Equation (2) reduces to

$$
u^{\prime}=-\frac{1}{2} v^{\prime 2}
$$

The neutral surface, $y_{n}$, changes for each section and can be obtained as

$$
y_{n}=\left\{\begin{array}{c}
0, \quad s<l_{1} \text { or } s>l_{2} \\
\frac{E_{p} t_{p}\left(t_{p}+t_{b}\right)}{2\left(E_{p} t_{p}+E_{b} t_{b}\right)}, l_{1}<s<l_{2}
\end{array}\right.
$$

The total kinetic energy $(\mathcal{T})$ of the system can be expressed as (Mahmoodi and Jalili 2007)

$$
\mathcal{T}=\frac{1}{2} \int_{0}^{l}\left[m(s)\left(\dot{u}^{2}+\dot{v}^{2}\right)+J(s)\left(\dot{v}^{\prime 2}-2 \dot{v}^{\prime 2} u^{\prime}-2 v^{\prime} \ddot{u}^{\prime} \dot{v}^{\prime}-2 \dot{v}^{\prime 2} v^{\prime 2}\right)\right] d s
$$

where,

$$
m(s)=b\left(\rho_{b} t_{b}+\left(H_{l_{1}}-H_{l_{2}}\right) \rho_{p} t_{p}\right)
$$

Here, $H(s)$ is the Heaviside function and $J(s)$ is the mass moment of inertia of the wing. 
Similarly, the total potential energy $(\mathcal{V})$ of the system can be written as (Mahmoodi and Jalili 2007)

$$
\begin{array}{r}
\mathcal{V}=\frac{1}{2} \int_{0}^{l_{1}} \iint_{A} \sigma_{11}^{b} \varepsilon_{11}^{b} d A d s+\frac{1}{2} \int_{l_{1}}^{l_{2}} \iint_{A} \sigma_{11}^{b} \varepsilon_{11}^{b} d A d s+\frac{1}{2} \int_{l_{1}}^{l_{2}} \iint_{A}\left(\sigma_{11}^{p} \varepsilon_{11}^{p}+Q_{2} D_{2}\right) d A d s \\
+\frac{1}{2} \int_{l_{2}}^{l} \iint_{A} \sigma_{11}^{b} \varepsilon_{11}^{b} d A d s+\frac{1}{2} \int_{0}^{l} E A(s)\left(u^{\prime 2}+u^{\prime} v^{\prime 2}+\frac{1}{4} v^{\prime 4}\right) d s
\end{array}
$$

The following fundamental assumptions are made for the analysis:

a) The wing is inextensible,

b) Bonding layer is assumed to be perfect,

c) Both, the piezoelectric layer and the wing have same width,

d) The wing is initially straight and it is clamped at one end and free at other end, and

e) The Euler-Bernoulli beam theories are followed, where shear deformation and rotary inertia terms are negligible.

Considering all the assumptions and applying the extended Hamilton's principle, governing equations of motion can be obtained as

$$
\begin{aligned}
m(s) \ddot{v} & +\frac{\partial^{2}}{\partial s^{2}}\left(C_{\zeta}(s) v^{\prime \prime}\right)+\frac{\partial}{\partial s}\left[v^{\prime} \int_{l}^{s} m(s) \int_{0}^{s}\left(\ddot{v} v^{\prime}+\dot{v}^{2}\right) d s d s\right]+\left[v^{\prime} \frac{\partial^{2}}{\partial s^{2}}\left(C_{\zeta}(s) v^{\prime \prime} v^{\prime}\right)+v^{\prime \prime} \frac{\partial}{\partial s}\left(C_{\zeta}(s) v^{\prime \prime} v^{\prime}\right)\right] \\
& +v^{\prime} \frac{\partial}{\partial s}\left(\frac{C_{d}^{2}(s)}{C_{\beta}(s)} v^{\prime \prime} v^{\prime}-\frac{b C_{c}(s)}{C_{\beta}(s)} P_{e}(t) v^{\prime}\right)-\frac{\partial^{2}}{\partial s^{2}}\left[\frac{b C_{d}(s)}{C_{\beta}(s)} P_{e}(t)\left(1-\frac{1}{2} v^{\prime 2}\right)+\frac{C_{d}^{2}(s)}{C_{\beta}(s)} v^{\prime \prime}\right]=0
\end{aligned}
$$

with the boundary conditions

$$
v(0, t)=v^{\prime}(0, t)=v^{\prime \prime}(l, t)=v^{\prime \prime \prime}(l, t)=0
$$

where

$$
\begin{gathered}
C_{\varsigma}(s)=\left(H_{0}-H_{l_{1}}\right) E_{b} I_{b}+\left(H_{l_{1}}-H_{l_{2}}\right) E_{b}\left(I_{b}+b t_{b} y_{n}^{2}\right) \\
+\left(H_{l_{1}}-H_{l_{2}}\right) E_{p} I_{p}+\left(H_{l_{2}}-H_{l}\right) E_{b} I_{b} \\
C_{d}(s)=\left(H_{l_{1}}-H_{l_{2}}\right) h_{12} I_{d} \\
C_{\beta}(s)=\left(H_{l_{1}}-H_{l_{2}}\right) b t_{b} \beta_{22}
\end{gathered}
$$




$$
\begin{aligned}
& I_{p}=b\left(t_{p} y_{n}^{2}+\left(t_{p}^{2}+t_{b} t_{p}\right) y_{n}+\frac{1}{3}\left(t_{p}^{3}+\frac{2}{3} t_{b} t_{p}+\frac{3}{4} t_{b}^{2} t_{p}\right)\right) \\
& I_{d}=\frac{b}{2}\left(t_{b} t_{p}+t_{p}^{2}-2 t_{p} y_{n}\right) \\
& I_{b}=\frac{b t_{b}^{3}}{12}
\end{aligned}
$$

Coupling of electrical and mechanical fields introduces quadratic and cubic nonlinearities due to piezoelectric effect. Cubic non-linear terms of inertia and stiffness, resulting from the geometry of the vibrating wing, appear in the equations of motion. The Galerkin method is utilized to discretize the system as

$$
v(s, t)=\sum_{n=1}^{\infty} v_{n}(s, t)=\sum_{n=1}^{\infty} \phi_{n}(s) q_{n}(t)
$$

where $\phi_{n}$ are companion functions and $q_{n}$ are generalized time-dependent coordinates. In order to solve the equations of motion utilizing the method of multiple scales (Nayfeh and Mook 1979), Equation (8) is rewritten in the form:

$$
\ddot{q}_{n}+\varepsilon \mu \dot{q}_{n}+\omega_{n}^{2} q_{n}+\varepsilon^{2} k_{1 n} f(t) q_{n}^{2}+\varepsilon k_{2 n} q_{n}^{3}+\varepsilon k_{3 n}\left(q_{n}^{2} \ddot{q}_{n}+q_{n} \dot{q}_{n}^{2}\right)+\varepsilon k_{4 n} f(t)=0
$$

where

$$
\begin{gathered}
\omega_{n}^{2}=\frac{g_{2 n}}{g_{1 n}}, k_{1 n}=\varepsilon^{-1} \frac{g_{3 n}}{g_{1 n}}, k_{2 n}=\varepsilon^{-1} \frac{g_{4 n}}{g_{1 n}}, k_{3 n}=\varepsilon^{-1} \frac{g_{5 n}}{g_{1 n}}, k_{4 n}=\varepsilon^{-1} \frac{g_{6 n}}{g_{1 n}}, f_{n}(t)=\varepsilon^{-1} P_{e}(t) \\
g_{1 n}=\int_{0}^{l} m(s)\left[\phi_{n}(s)\right]^{2} d s \\
g_{2 n}=\int_{0}^{l} C_{\zeta}(s) \phi_{n}^{\prime \prime}(s) d s-\frac{h_{12} I_{d}\left(\phi_{n}^{\prime}\left(l_{2}\right)-\phi_{n}^{\prime}\left(l_{1}\right)\right)}{b t_{p} \beta_{22}\left(l_{2}-l_{1}\right)} \int_{0}^{l} C_{d}(s) \phi_{n}^{\prime \prime}(s) d s \\
g_{3 n}=\frac{1}{t_{p} \beta_{22}} \int_{0}^{l} C_{d}(s) \phi_{n}^{\prime \prime}(s)\left[\phi_{n}^{\prime}(s)\right]^{2} d s \\
g_{4 n}=2 \int_{0}^{l} C_{\zeta}(s)\left[\phi_{n}^{\prime \prime}(s)\right]^{2} d s-\frac{h_{12} I_{d}\left(\left[\phi_{n}^{\prime}\left(l_{2}\right)\right]^{3}-\left[\phi_{n}^{\prime}\left(l_{1}\right)\right]^{3}\right)}{b t_{p} \beta_{22}\left(l_{2}-l_{1}\right)} \int_{0}^{l} C_{d}(s) \phi_{n}^{\prime \prime}(s) d s \\
-\frac{h_{12} I_{d}\left(\phi_{n}^{\prime}\left(l_{2}\right)-\phi_{n}^{\prime}\left(l_{1}\right)\right)}{b t_{p} \beta_{22}\left(l_{2}-l_{1}\right)} \int_{0}^{l} C_{d}(s) \phi_{n}^{\prime \prime}(s)\left[\phi_{n}^{\prime}(s)\right]^{2} d s
\end{gathered}
$$




$$
\begin{gathered}
g_{5 n}=2 \int_{0}^{l} \phi_{n}(s)\left[m(s) \phi_{n}^{\prime}(s) \int_{l}^{s} \int_{0}^{s} 2\left[\phi_{n}^{\prime}(s)\right]^{2} d s d s\right]^{\prime} d s \\
g_{6 n}=\frac{1}{t_{p} \beta_{22}} \int_{0}^{l} C_{d}(s) \phi_{n}^{\prime \prime}(s) d s
\end{gathered}
$$

The linear mode shapes of a cantilever beam are considered here to be the following companion functions:

$$
\phi_{n}(x)=\cosh \left(z_{n} x\right)-\cos \left(z_{n} x\right)+\left[\sin \left(z_{n} x\right)-\sinh \left(z_{n} x\right)\right] \frac{\cosh \left(z_{n}\right)+\cos \left(z_{n}\right)}{\sinh \left(z_{n}\right)+\sin \left(z_{n}\right)}
$$

where $z_{n}$ are the roots of the frequency equation

$$
1+\cos \left(z_{n}\right) \cosh \left(z_{n}\right)=0
$$

Now, $q_{n}(t)$ can be expressed by order of $\varepsilon$ as (Nayfeh 1973)

$$
q_{n}(t ; \varepsilon)=q_{0 n}\left(T_{0}, T_{1}\right)+\varepsilon q_{1 n}\left(T_{0}, T_{1}\right)+\cdots
$$

where, $T_{0}$ and $T_{1}$ are the time scales. $T_{1}=\varepsilon t$ is defined shift in the natural frequencies because of the non-linearity, while $T_{o}=t$ demonstrates motion occurring at the natural frequencies, $\omega_{n}$. Frequency response of the system can be expressed as

$$
\left(\frac{1}{2} \mu \omega_{n} a_{n}\right)^{2}+\left(\frac{3}{8} k_{2 n} a_{n}^{3}-\omega_{n}^{2} \sigma a_{n}\right)^{2}=k_{4 n}^{2} f^{2}
$$

where $\sigma$ is a detuning parameter and $a_{n}$ is the amplitude of the generalized coordinate $q_{n}(t)$. Finally, the deflection at the tip of the wing is obtained by

$$
v(l, t)=\phi_{n}(l) a_{n}(t) \cos \left(\beta_{n} t+\beta_{0}\right)=\phi(l) q(t)
$$

where $a_{n}$ and $\beta_{n}$ are real functions of time scale.

\section{Aerodynamic Model}

The aerodynamic model is based on the modified strip theory as proposed by DeLaurier (1993), in which the aerodynamic forces of the flapping wing are obtained by integrating the sectional aerodynamic forces calculated in each section. Recently, Kim et al. (2011) improved modified strip theory to consider dynamic stall for a high relative angle of attack and compared the present aerodynamic model's results with the experimental data of a flat plate wing with oscillating motion. Further, Lee et al. (2011) used this model to 
study the flapping frequency-dependent trim flight characteristics of a bioinspired ornithopter. In the present study DeLaurier's aerodynamic model is used for the aerodynamic analysis and DeLaurier's model is a well validated model and several researchers (Madangopal et al. 2005, Ke et al. 2008) have used it in order to estimate the aerodynamic performance of harmonically flapping wings in the phase of preliminary design and development. In this unsteady aerodynamic model, the kinematics for a section of the wing is represented by a plunging velocity $\dot{h}$ and a pitch angle of the chord $\theta$ relative to the free stream velocity, as shown in Fig. 3.

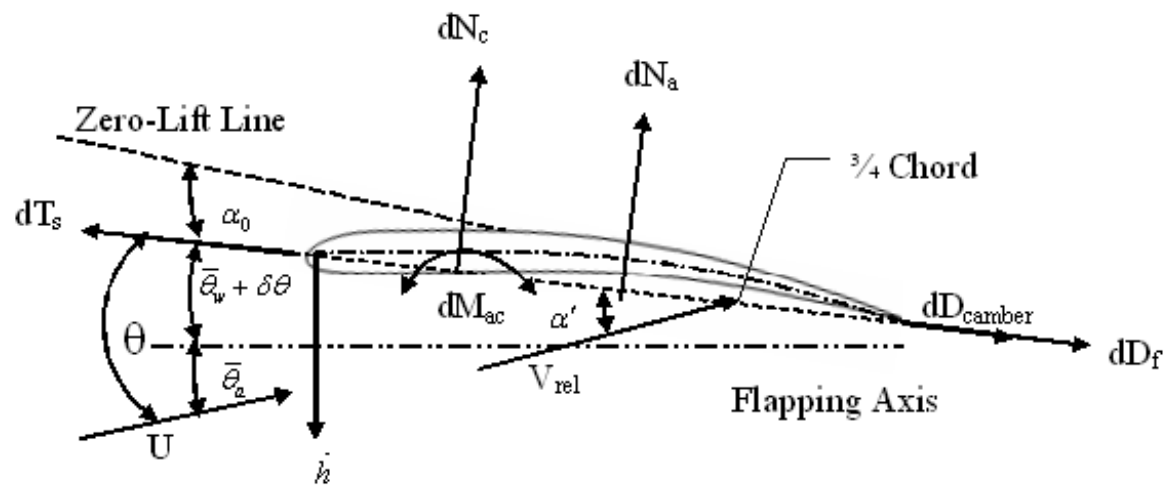

Fig. 3 Aerodynamic forces and motion variables of a wing section

The aerodynamic forces acting on each section of the wing are divided into the normal force $d N$, and the chordwise force, $d F_{X}$. The local parameters determining the forces includes the section's geometry, relative angle of attack at the $3 / 4$-chord location, pitch rates and the dynamic pressure at the 1/4-chord location. The components of the normal force are: (i) $d N_{c}$, a circulatory force normal to the chord at the 1/4-chord location and (ii) $d N_{a}$, an apparent-mass force normal to the chord at the $1 / 2$-chord location. The expressions for the normal force components are as follows:

$$
\begin{gathered}
d N_{c}=\frac{\rho_{a i r} U V}{2} C_{n} c d y \\
d N_{a}=\frac{\rho_{a i r} \pi c^{2}}{4} \dot{v}_{2} d y
\end{gathered}
$$

Therefore, the section's total attached flow normal force is

$$
d N=d N_{c}+d N_{a}
$$

The components of the chordwise force are: (i) $d T_{s}$, a chordwise leading edge suction force, (ii) $d D_{\text {camber }}$, a chordwise drag due to camber, and (iii) $d D_{f}$, a chordwise drag due to skin friction. The expressions for the chordwise force components are as follows: 


$$
\begin{gathered}
d T_{s}=\eta_{s} 2 \pi\left(\alpha^{\prime}+\bar{\theta}_{a}-\frac{c \dot{\theta}}{4 U}\right)^{2} \frac{\rho_{a i r} U V}{2} c d y \\
d D_{\text {camber }}=-2 \pi \alpha_{0}\left(\alpha^{\prime}+\bar{\theta}_{a}+\bar{\theta}_{w}\right) \frac{\rho_{a i r} U V}{2} c d y \\
d D_{f}=\left(C_{d}\right)_{f} \frac{\rho_{a i r} V_{x}^{2}}{2} c d y
\end{gathered}
$$

Thus, the total chordwise force is

$$
d F_{X}=d T_{s}-d D_{\text {camber }}-d D_{f}
$$

The equations for the segment's instantaneous lift $d L$ and thrust $d T$ are

$$
\begin{aligned}
& d L=d N \cos \theta+d F_{X} \sin \theta \\
& d T=d F_{X} \cos \theta-d N \sin \theta
\end{aligned}
$$

These may be integrated along the span to give the whole wing's instantaneous lift and thrust:

$$
\begin{gathered}
L(t)=2 \int_{0}^{\frac{b}{2}} \cos \gamma d L \\
T(t)=2 \int_{0}^{\frac{b}{2}} d T
\end{gathered}
$$

where $\gamma(t)$ is the section's dihedral angle at that instant in the flapping cycle.

The wing's average lift and thrust are obtained by integrating $L(t)$ and $T(t)$ over the cycle. Integrating with respect to cycle angle, $\phi$, instead of time, $t$, where

$$
\phi=\omega t
$$

so that the average lift and thrust are expressed as

$$
\begin{aligned}
& \bar{L}=\frac{1}{2 \pi} \int_{0}^{2 \pi} L(\phi) d \phi \\
& \bar{T}=\frac{1}{2 \pi} \int_{0}^{2 \pi} T(\phi) d \phi
\end{aligned}
$$

The complete details of the aerodynamic model are given by DeLaurier (1993). 


\section{Results and Discussion}

The results of the numerical simulations are shown in three sections. First, the implementation of the nonlinear analysis for the piezoelectrically actuated microcantilever beam is discussed. Next, the model is used to perform dynamic analysis of dragonfly inspired flapping wings. Finally, the aerodynamic analysis of the flapping wing is done and best design for the flapping wing is identified and evaluated.

\subsection{Validation of numerical analysis}

In order to validate the dynamic model, numerical analysis is carried out for a structure which is used by Mahmoodi and Jalili (2007) as shown in Fig. 4. The physical properties, used for this analysis are given in Table 1.

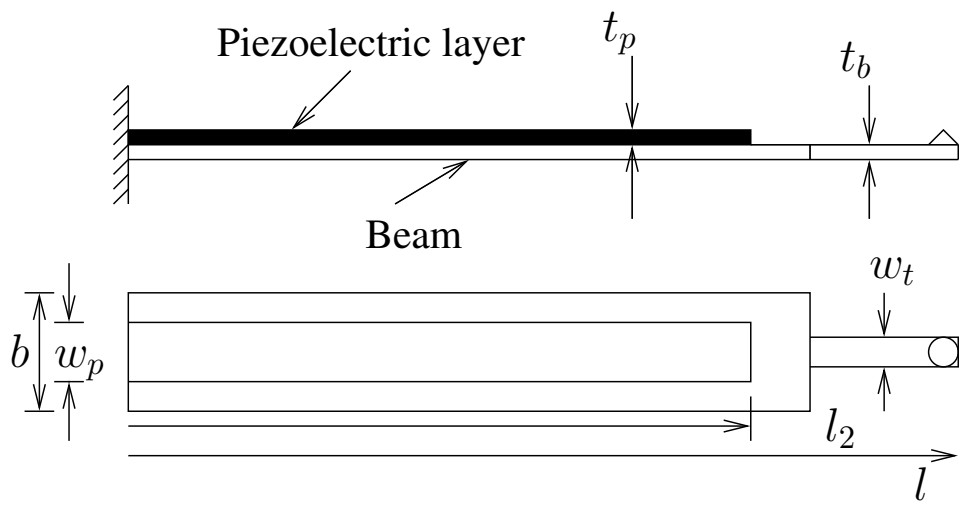

Fig. 4 Geometry of the microcantilever beam

Table 1 Material and geometric properties used for model validation

\begin{tabular}{llll}
\hline \hline \multicolumn{2}{c}{ Microcantilever beam } & \multicolumn{2}{c}{ Piezoelectric Layer } \\
\hline Parameter & \multicolumn{1}{c}{ Value } & \multicolumn{1}{c}{ Parameter } & Value \\
\hline Young's modulus & $105 \mathrm{GPa}$ & Young's modulus & $104 \mathrm{GPa}$ \\
Beam length & $500 \mu \mathrm{m}$ & Piezoelectric length & $375 \mu \mathrm{m}$ \\
Width & $250 \mu \mathrm{m}$ & Width & $130 \mu \mathrm{m}$ \\
Tip mass width & $55 \mu \mathrm{m}$ & Coupling coefficient & $500 \mathrm{MV} / \mathrm{m}$ \\
Poisson's ratio & 0.28 & Poisson's ratio & 0.25 \\
Density & $2330 \mathrm{Kg} / \mathrm{m}^{3}$ & Density & $6390 \mathrm{Kg} / \mathrm{m}^{3}$ \\
Thickness & $4 \mu \mathrm{m}$ & Thickness & $4 \mu \mathrm{m}$ \\
\hline
\end{tabular}

Fig. 5 shows the tip deflection due to the excitation voltage of $0.5 \mathrm{Vpp}$. Excitation voltage is increased to $1.5 \mathrm{Vpp}$ and the corresponding tip deflection is shown in Fig. 6. It can be seen from Fig. 5 and Fig. 6 that tip deflection is sensitive to the input excitation voltage. Moreover, the results of this analysis match well with the results presented in Mahmoodi and Jalili (2007). Therefore, the model implementation is validated and subsequently used for dynamic analysis of dragonfly inspired smart flapping wings. 


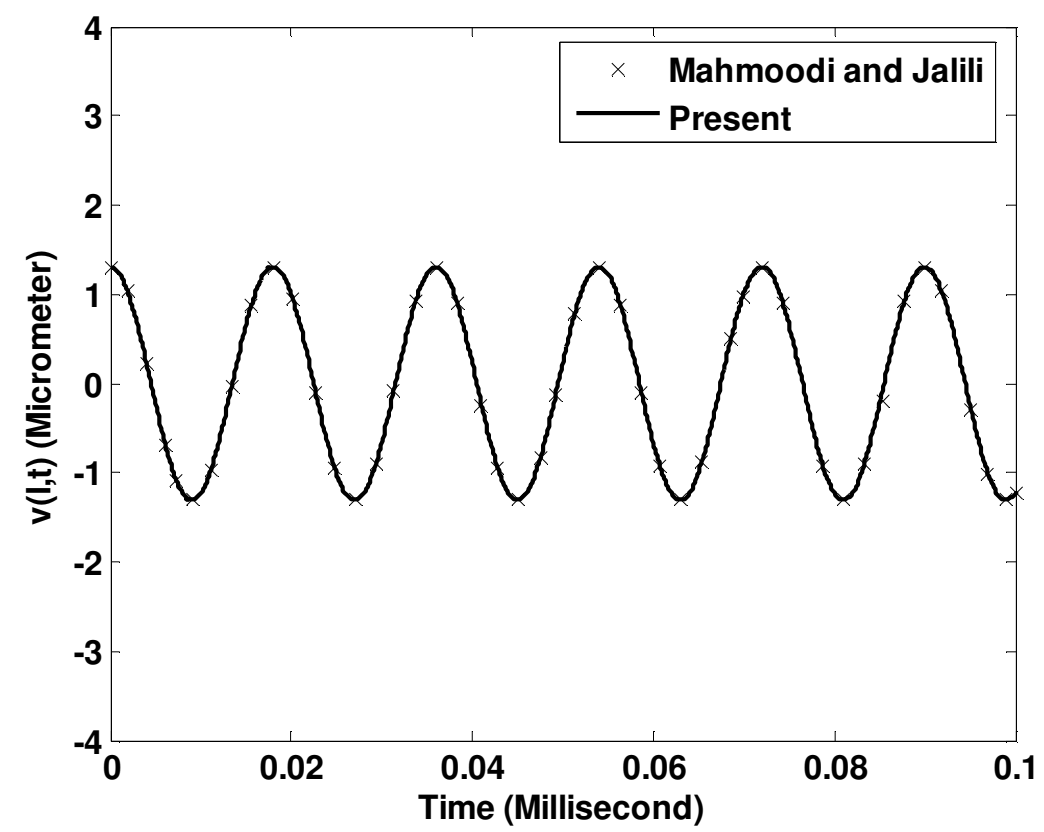

Fig. 5 Tip deflection due to $0.5 \mathrm{Vpp}$ excitation

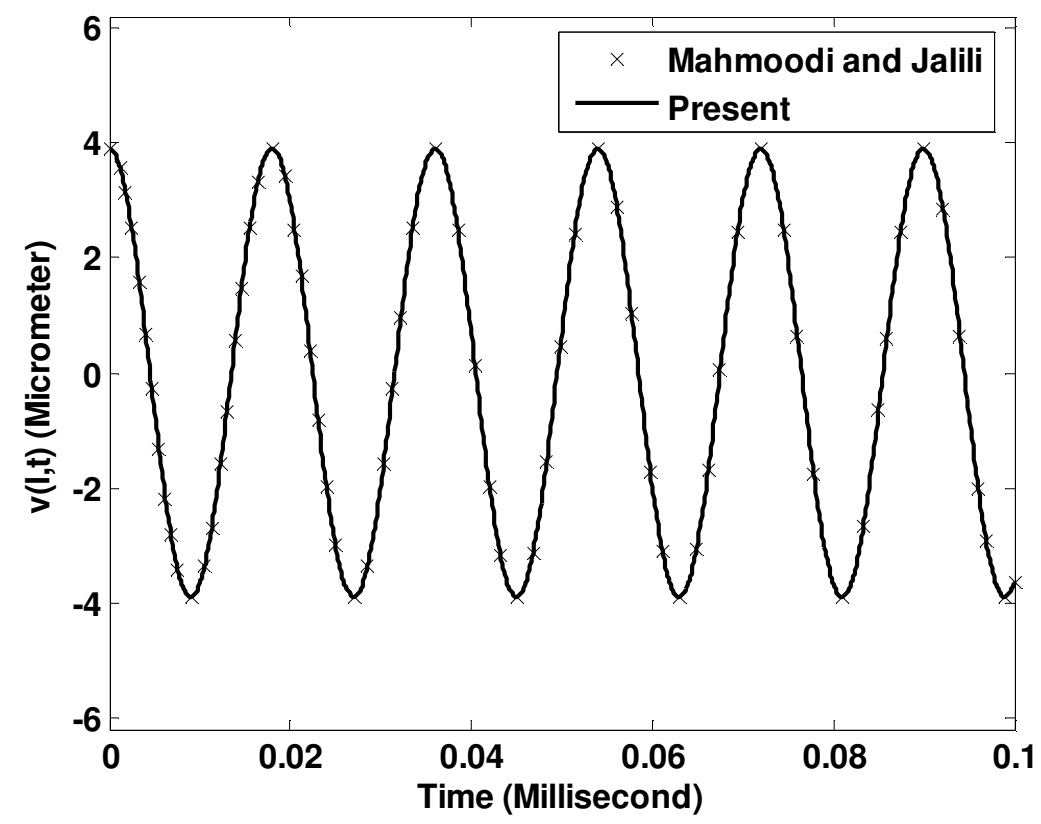

Fig. 6 Tip deflection due to 1.5 Vpp excitation

\subsection{Dynamic analysis of flapping wing}

In the present study, the sizes of the flapping wings are chosen at an insect scale. Insects, such as the dragonfly, fly with unusual aerial agility. Dragonfly flight satisfies all the requirements of an MAV flight envelope therefore providing inspiration for MAV design. 
Dragonfly wing size shows substantial variations among the different species due to demographical reasons. Fig. 7 shows the picture of three different dragonfly species. Planforms of wings of three different dragonfly species and their typical average values are shown in Fig. 8. These three species provide wings with considerably different lengths and widths. Thus, they are different biomimetic designs for flapping wing MAVs.

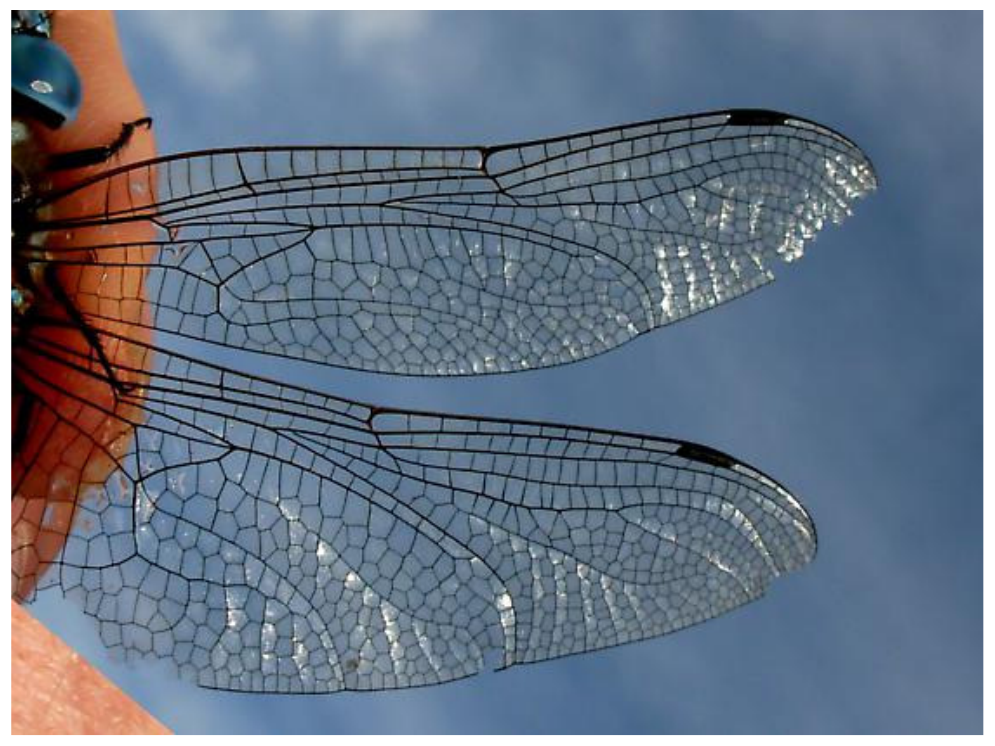

(a) Dragonfly Aeshna Multicolor

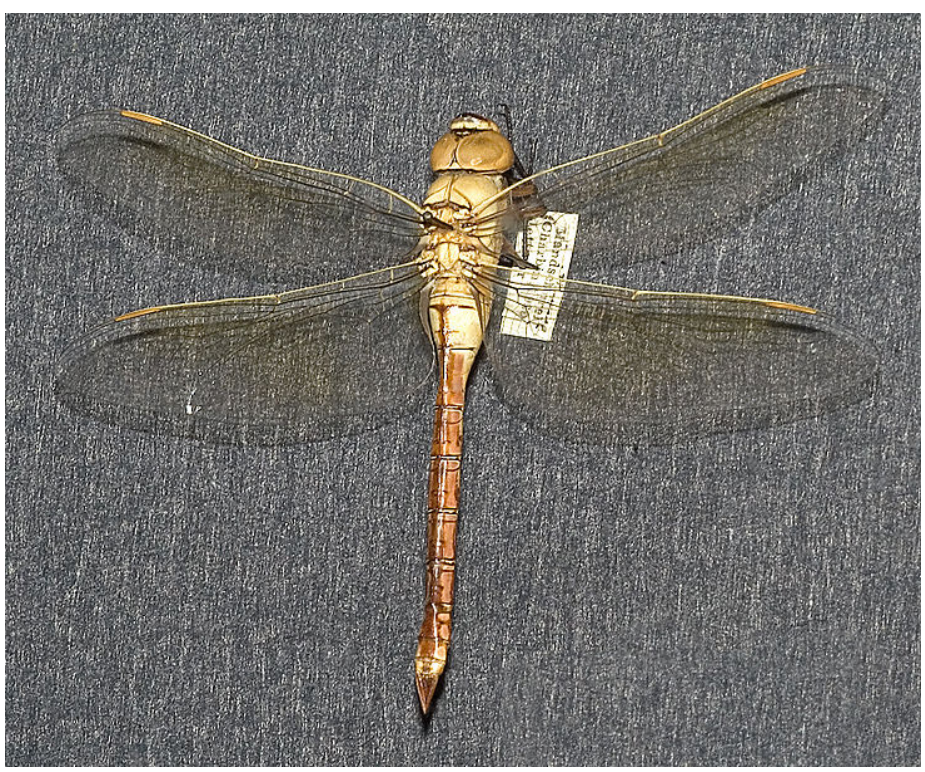

(b) Dragonfly Anax Parthenope Julius 


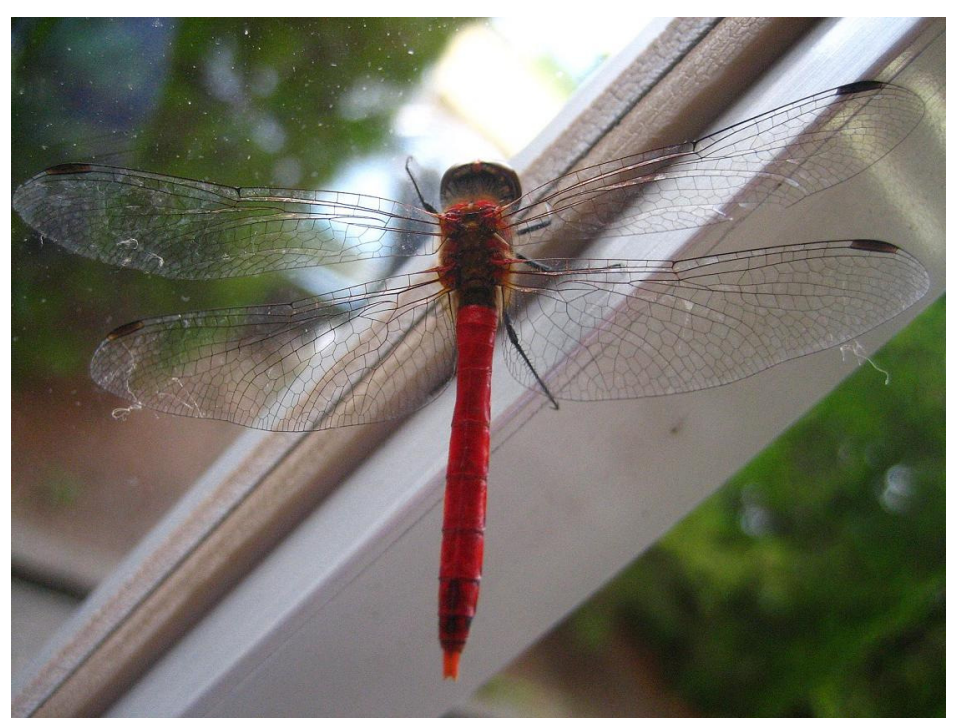

(c) Dragonfly Sympetrum Frequens

Fig. 7 Picture of three different dragonfly species used for biomimetic inspiration

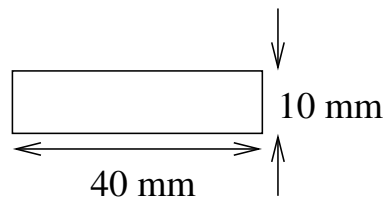

(a)

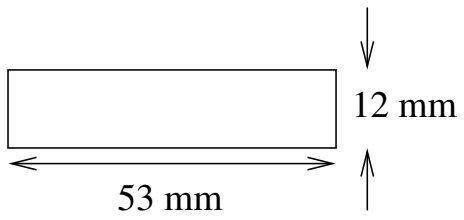

(b)

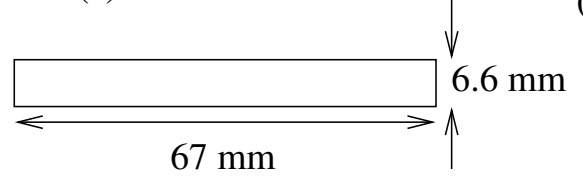

(c)

Fig. 8 Schematic diagram of the planform of smart wings having the same size as (a) Aeshna Multicolor wing (Combes and Daniel 2003), (b) Anax Parthenope Julius wing

(Sunada et al. 1998) and (c) Sympetrum Frequens wing (Azuma et al. 1985)

Flapping wing corresponding to each dragonfly species is considered for dynamic analysis. Wings are made of Mylar and actuated from the root by a piezoceramic unimorph in the piezofan configuration as shown in Fig. 1. In the present study, both PZT-5H and PZN-7\%PT single crystal piezoceramics are considered for flapping wing actuation and they are schematically shown in Fig. 9. Input excitation voltage is assumed to be harmonic to generate flapping motion. Material properties pertaining to each flapping wing are given in Table 2. Here, the thickness of piezo layer and Mylar wing is considered to be $200 \mu \mathrm{m}$. These properties are used to analyze the performances of the dragonfly inspired flapping wings. 
Table 2 Material properties of the flapping wings

\begin{tabular}{lll}
\hline \hline & \multicolumn{1}{c}{ Parameter } & Value \\
\hline $\begin{array}{lll}\text { Mylar } \\
\text { (Wait } \text { et al. 2007) }\end{array}$ & Young's modulus & $4.6 \mathrm{GPa}$ \\
& $\begin{array}{l}\text { Density } \\
\text { Poisson's ratio }\end{array}$ & $1240 \mathrm{Kg} / \mathrm{m}^{3}$ \\
PZT-5H & Young's modulus & 0.44 \\
(Chung et al. 2009) & $\begin{array}{l}\text { Density } \\
\text { Piezoelectric constant }\left(\mathrm{d}_{31}\right)\end{array}$ & $62 \mathrm{GPa}$ \\
& $-3200 \times 10^{-12} \mathrm{~m} / \mathrm{V}$ \\
PZN-7\%PT & Young's modulus & $126.5 \mathrm{GPa}$ \\
(Zhang et al. 2002) & Density & $8350 \mathrm{Kg} / \mathrm{m}^{3}$ \\
(Zeng et al. 2008) & Piezoelectric constant $\left(\mathrm{d}_{31}\right)$ & $-1204 \times 10^{-12} \mathrm{~m} / \mathrm{V}$ \\
\hline
\end{tabular}
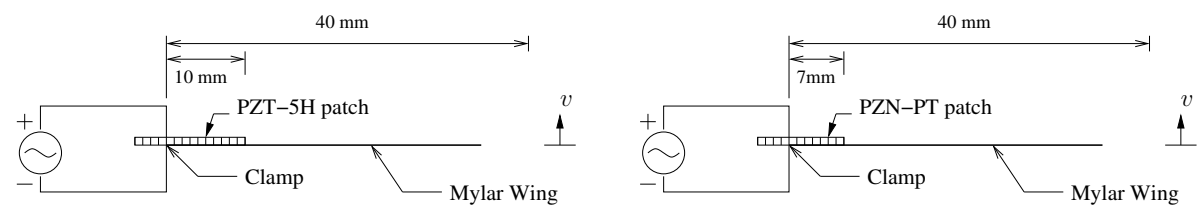

(a) Aeshna Multicolor flapping wing with PZT-5H and PZN-PT patches
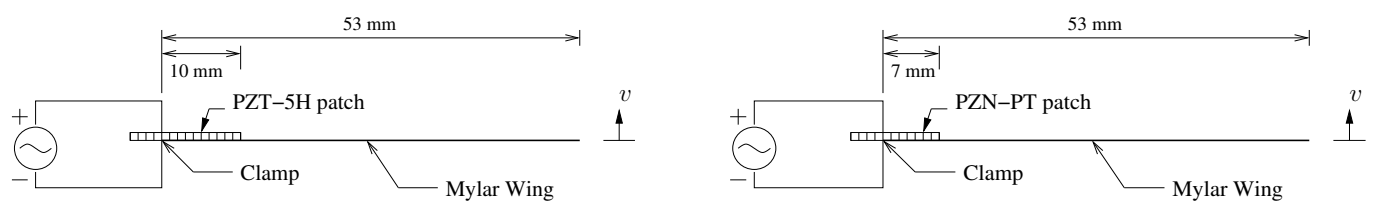

(b) Anax Parthenope Julius flapping wing with PZT-5H and PZN-PT patches
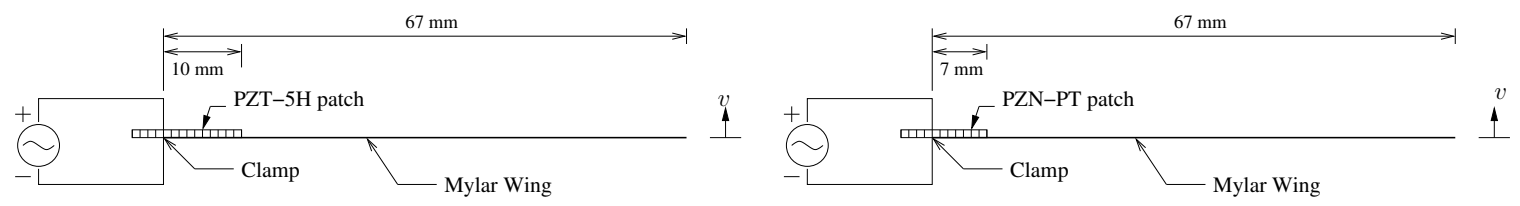

(c) Sympetrum Frequens flapping wing with PZT-5H and PZN-PT patches

Fig. 9 Schematic diagram of smart flapping wings inspired by three dragonfly species

It is clear from Table 3 that the piezoelectric constant $\left(\mathrm{d}_{31}\right)$ of PZN-7\%PT is nearly 4 times higher than that of PZT-5H. Therefore, it is possible to reduce the amount of piezoceramic material used for PZN-7\%PT wings as can be seen from Fig. 9. It is shown in Fig. 10 that the use of PZN-7\%PT can lead to a wing weight reduction up to 15\%, 13\% and $12 \%$ as compared to that of Aeshna Multicolor, Anax Parthenope Julius, Sympetrum Frequens PZT-5H wings, respectively. The length of the PZN-PT patch was reduced 
from $10 \mathrm{~mm}$ to $7 \mathrm{~mm}$ to approximately match the amplitude of the tip deflections in dynamic analysis, as discussed next. Numerical experiments with different piezo patch lengths were used to arrive at this design.

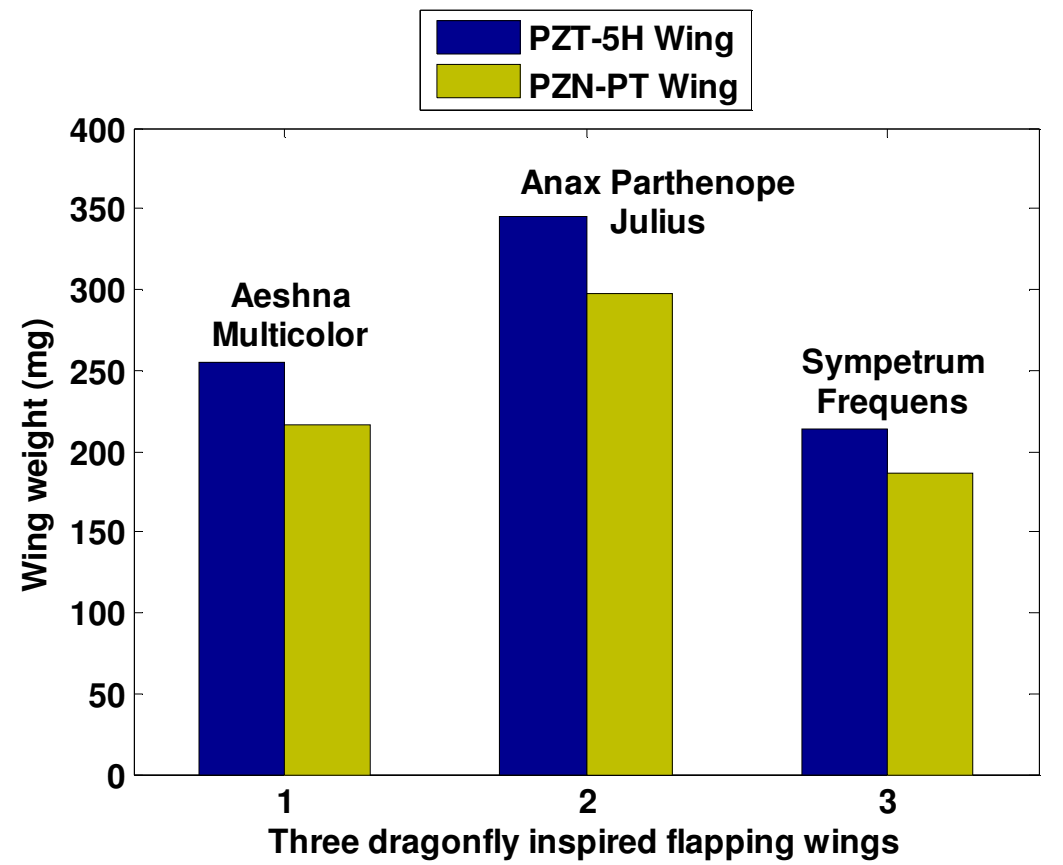

Fig. 10 Wing weight of three dragonfly inspired smart flapping wings

\subsubsection{Wing tip deflections}

The first set of results compares the tip response of the flapping wings inspired by the three different dragonfly species when actuated by the two different smart materials. Fig. 11 shows the tip deflections of the three different smart flapping wings actuated by PZT$5 \mathrm{H}$ and $\mathrm{PZN}-7 \% \mathrm{PT}$ at an excitation voltage of $60 \mathrm{~V}$ and excitation frequency corresponding to their respective first natural frequencies. A tip deflection of $21 \mathrm{~mm}$ is obtained for Aeshna Multicolor PZT-5H wing at $41 \mathrm{~Hz}$, as can be seen from Fig 11(a). Fig. 11(a) also shows that tip deflection of Aeshna Multicolor PZT-7\%PT is $24 \mathrm{~mm}$ at 38 Hz. Fig. 11(b) shows the maximum tip deflection of Anax Parthenope Julius PZT-5H wing is $37 \mathrm{~mm}$ and it occurs at $29 \mathrm{~Hz}$. Fig. 11(b) also shows that tip deflection of Anax Parthenope Julius PZN-7\%PT wing is $40 \mathrm{~mm}$ at $27 \mathrm{~Hz}$. Similarly, Fig. 11(c) shows that the maximum tip deflection of Sympetrum Frequens PZT-5H wing is $59 \mathrm{~mm}$ and it occurs at $21 \mathrm{~Hz}$. Fig. 11(c) also shows that tip deflection of Sympetrum Frequens PZT$7 \% \mathrm{PT}$ wing is $68.58 \mathrm{~mm}$ at $19 \mathrm{~Hz}$. It can be noted from the above results that a slightly higher tip deflection is obtained when the flapping wings are actuated by PZN-7\%PT as compared to PZT-5H. Thus we can see that good actuation performance can be obtained even after using less piezoelectric material, when single crystal actuation is used. 


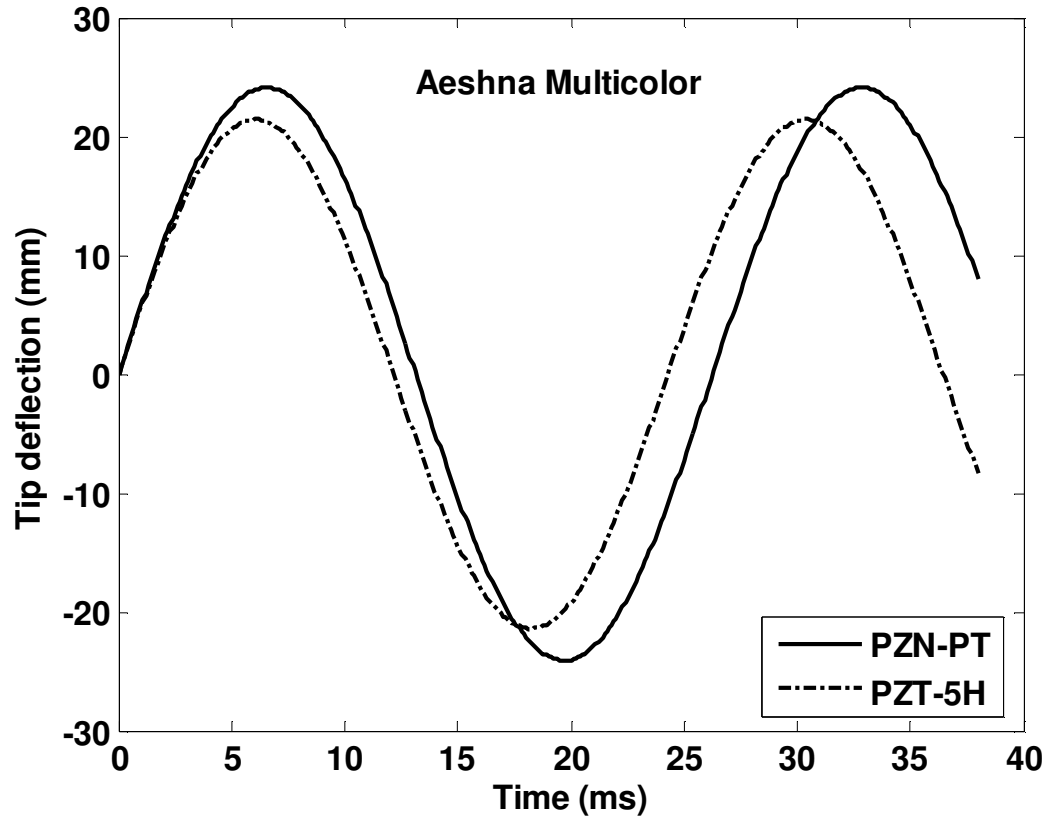

(a)

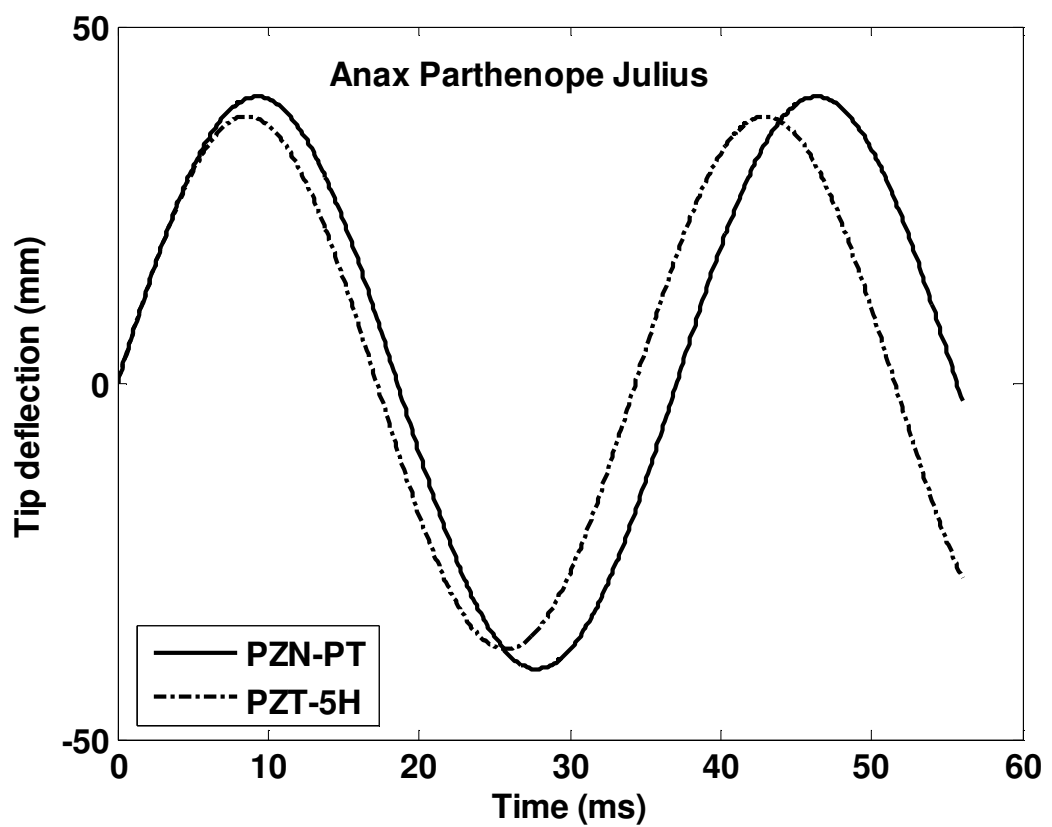

(b) 


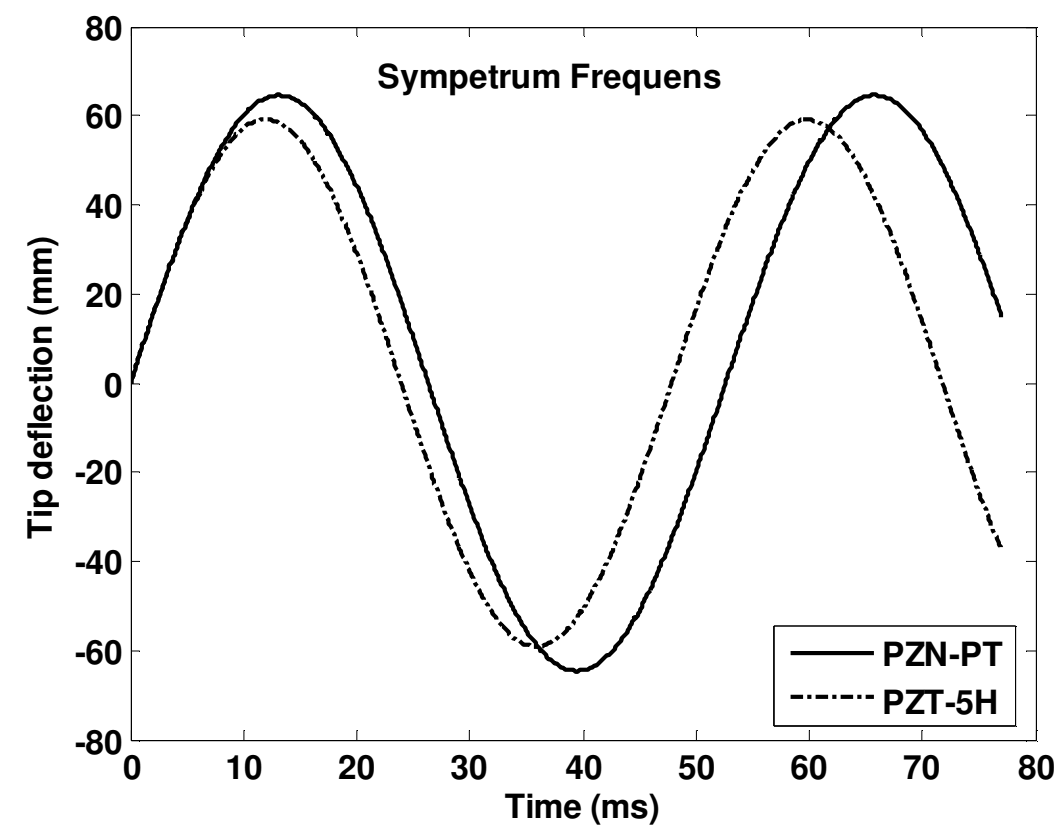

(c)

Fig. 11 Tip deflections of three dragonfly inspired smart flapping wings

It can be noted from the above results that the magnitude of the maximum tip deflection and frequency at which it occurs are different for each wing although their input excitation voltage is identical, i.e., $60 \mathrm{~V}$. This happens because of the difference between the wing geometries and the material properties. In turn, the flapping frequency of each wing and the flapping angle produced by each wing will also be different. We will see in a later part of this section that these parameters have substantial effect on the performance of each wing in terms of aerodynamic forces.

\subsubsection{Wing flapping angles}

The flapping angle is a good measure of the actuation performance of the smart materials used. The flapping angle can be obtained from the tip deflection following the procedure explained schematically in Fig. 12.

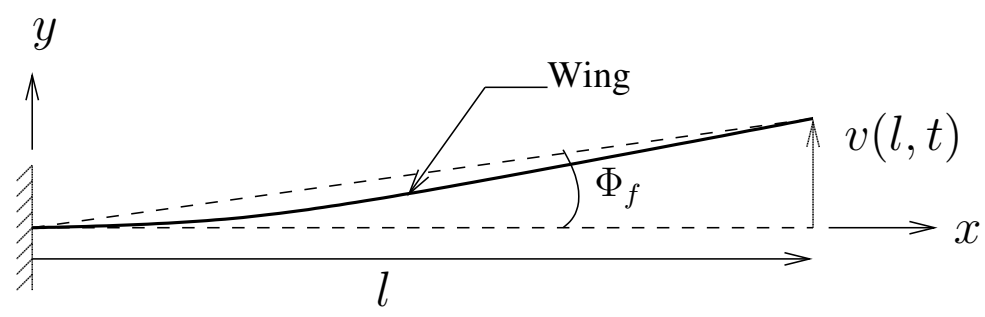

Fig. 12 Schematic diagram of calculating flapping angle 
Fig. 13 shows the flapping angle variations of smart flapping wings at an excitation voltage of $60 \mathrm{~V}$ for the flapping wings corresponding to the three different dragonfly species and two different piezoceramic materials. Fig. 13(a) shows that the Aeshna Multicolor wing produces flapping angles of $28^{\circ}$ and $31^{0}$ for PZT-5H and PZN-7\%PT wings, respectively. Fig. 13(b) shows that Anax Parthenope Julius wing with PZT-5H and PZN-7\%PT patch can produce flapping angles of $35^{\circ}$ and $37^{\circ}$, respectively. Fig. 13(c) shows that flapping angles reach up to $41^{\circ}$ and $44^{\circ}$ for Sympetrum Frequens wing with PZT-5H and PZN-7\%PT patch, respectively. The more flexible wings of Sympetrum Frequens with PZN-7\%PT patch are most suitable for high levels of flapping. Moreover, the above results show that the flapping angles produced by these wings belong to nonlinear regime. Therefore, nonlinear dynamic model is required to predict the response of these flapping wings accurately (Mukherjee and Ganguli 2010). While the dynamic analysis shows the high actuation capacity of smart materials, the key issue for MAV application is the lift generating capacity of the wing. Aerodynamic forces are obtained using an unsteady aerodynamic model as described in the next section.

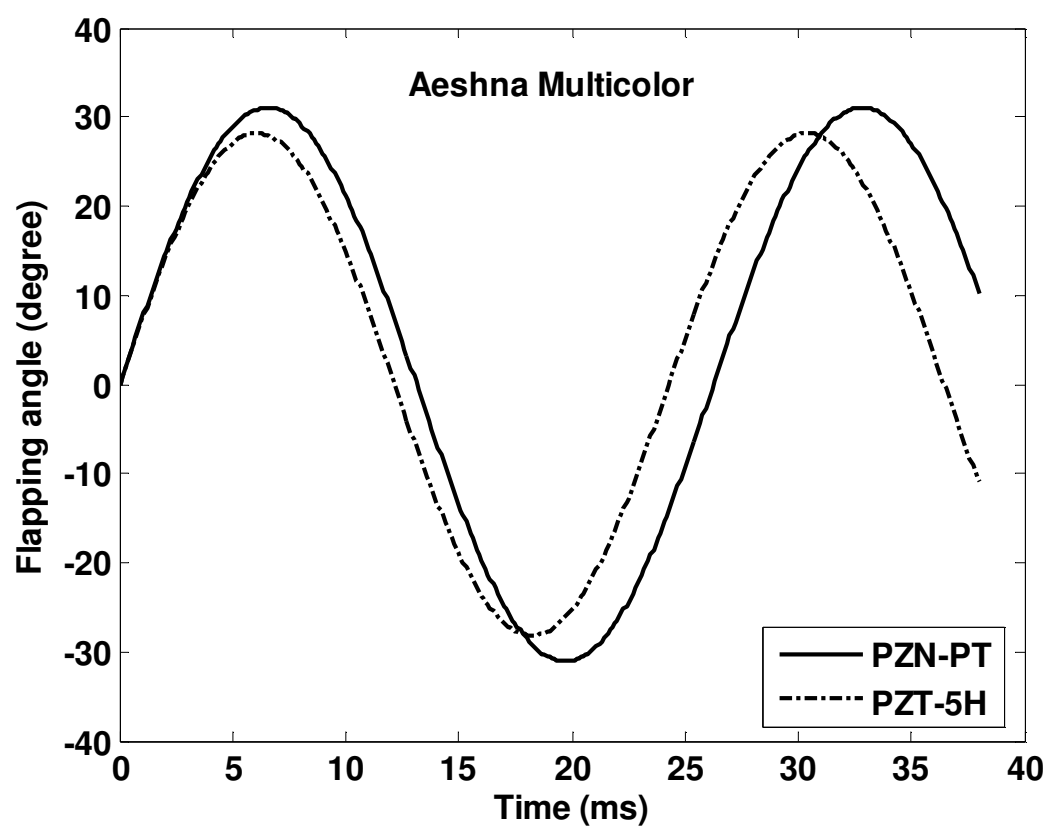

(a) 


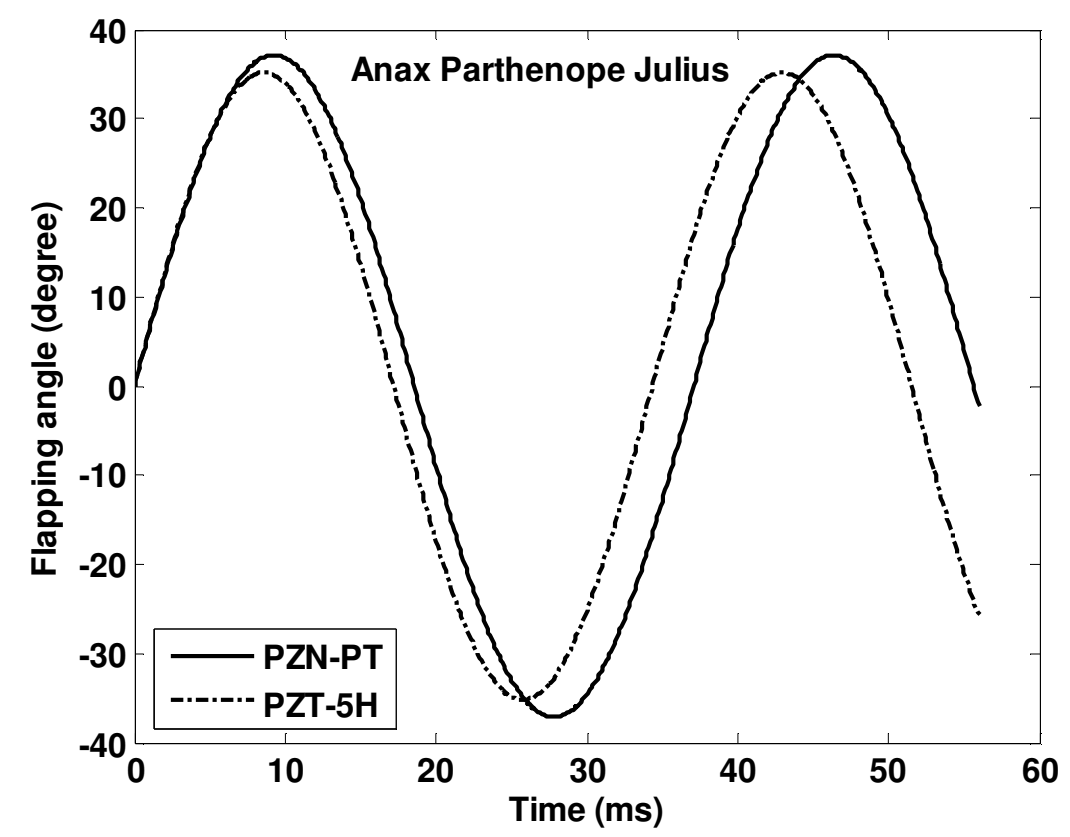

(b)

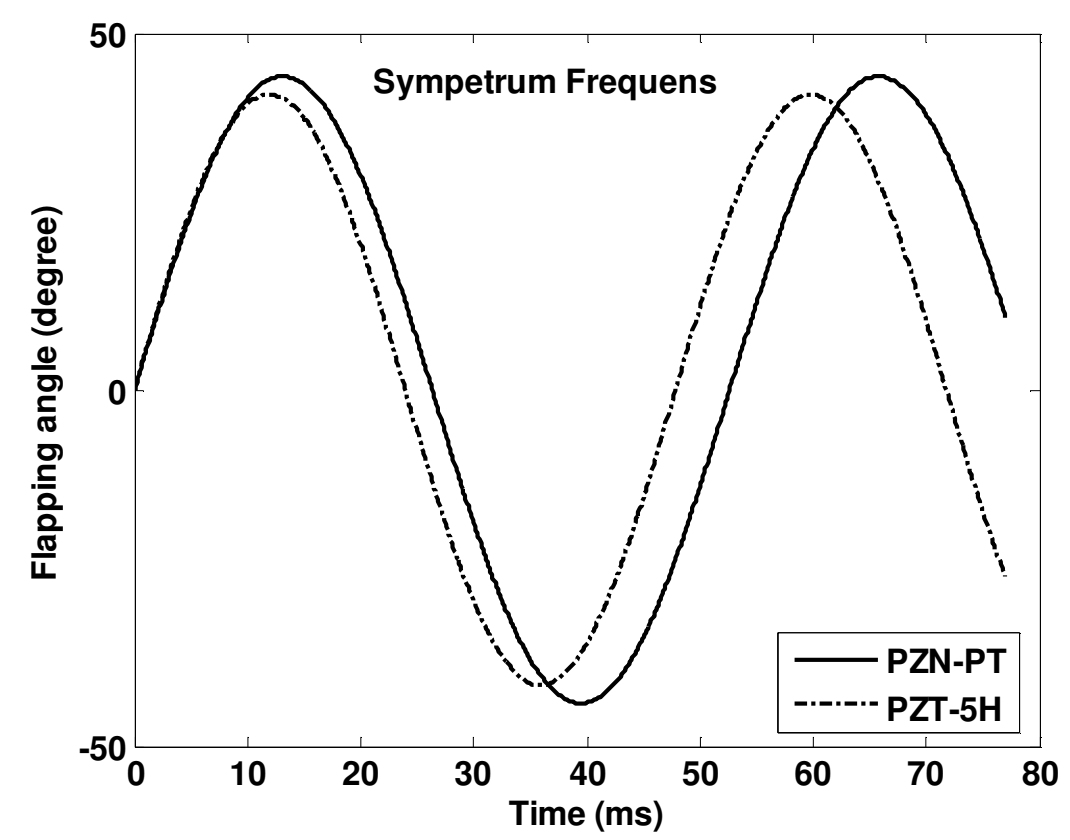

(c)

Fig. 13 Flapping angle variations of three dragonfly inspired smart flapping wings

\subsection{Aerodynamic analysis of flapping wing}

For aerodynamic modeling, kinematics pertaining to the wing section located at $75 \%$ of the wing span is considered for calculation of the aerodynamic forces. The aerodynamic 
forces are calculated at different pitch angles and different flight speeds and the net lift force generated by the flapping wing is found.

\subsubsection{Aerodynamic forces at different pitch angles}

Fig. 14 shows the average lift pertaining to each wing at different pitch angle $\left(\bar{\theta}_{a}\right)$ at a flight speed of $3 \mathrm{~m} / \mathrm{s}$ which is a typical flight speed for dragonflies. Average thrust at different pitch angles is shown in Fig. 15 where the wings inspired by the three different dragonfly species and two piezoceramic materials are compared. Fig. 14(a) shows that maximum average lift for Aeshna Multicolor wing occurs at the pitch angle of $7.8^{0}$ for both PZT-5H and PZN-7\%PT wings. Fig. 14(b) shows that the maximum average lift for Anax Parthenope Julius wing occurs at the pitch angle of $7.7^{0}$ for both PZT-5H and PZN7\%PT wings. Similarly, Fig. 14(c) shows that Sympetrum Frequens PZT-5H and PZN$7 \% \mathrm{PT}$ wing occur at the pitch angle of $7.7^{\circ}$ and $7.8^{\circ}$, respectively. However, it can be seen from Fig. 15 that thrust corresponding to each pitch angle, at which average lift reaches maximum, has a negative value. Since average thrust force must be positive to satisfy the condition for cruise flight, the value of pitch angle is selected as $7^{0}$ for each wing. From Figs. 14 and 15, it can be seen that the pitch angle of $7^{0}$ results in a reasonable level of lift along with positive thrust. After selecting the pitch angle of the flapping axis, average lift and thrust are obtained for each smart flapping wing by varying the flight speeds.

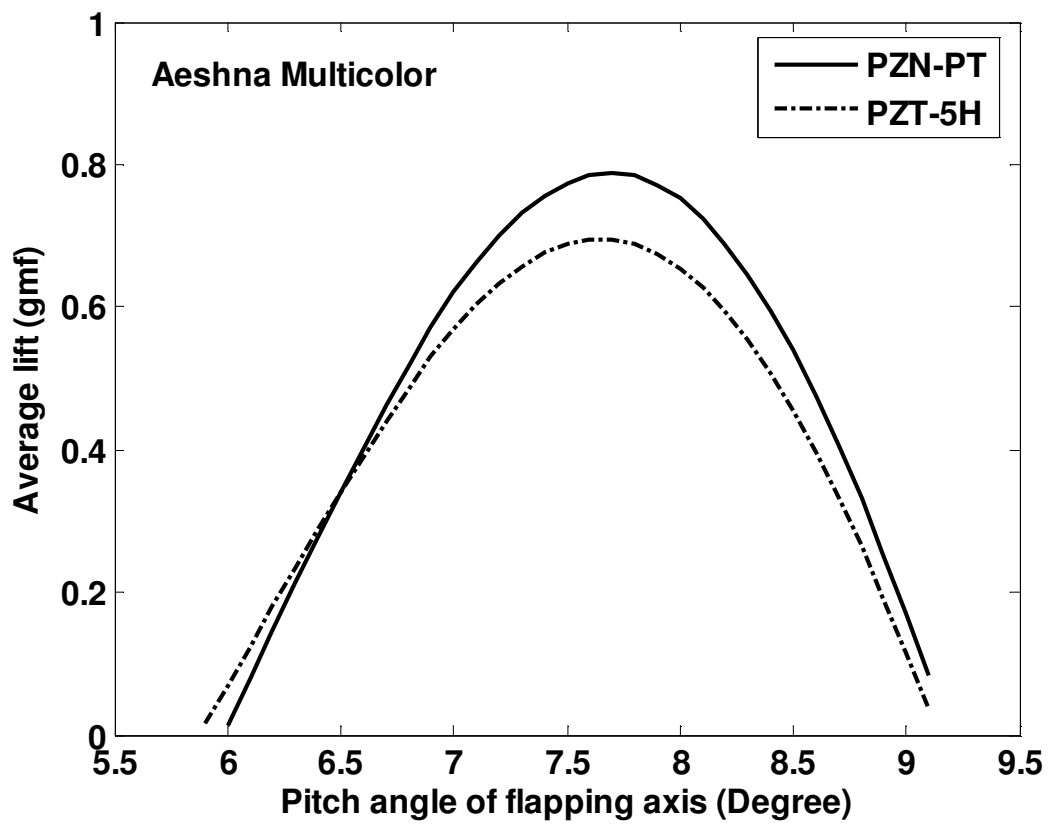

(a) 


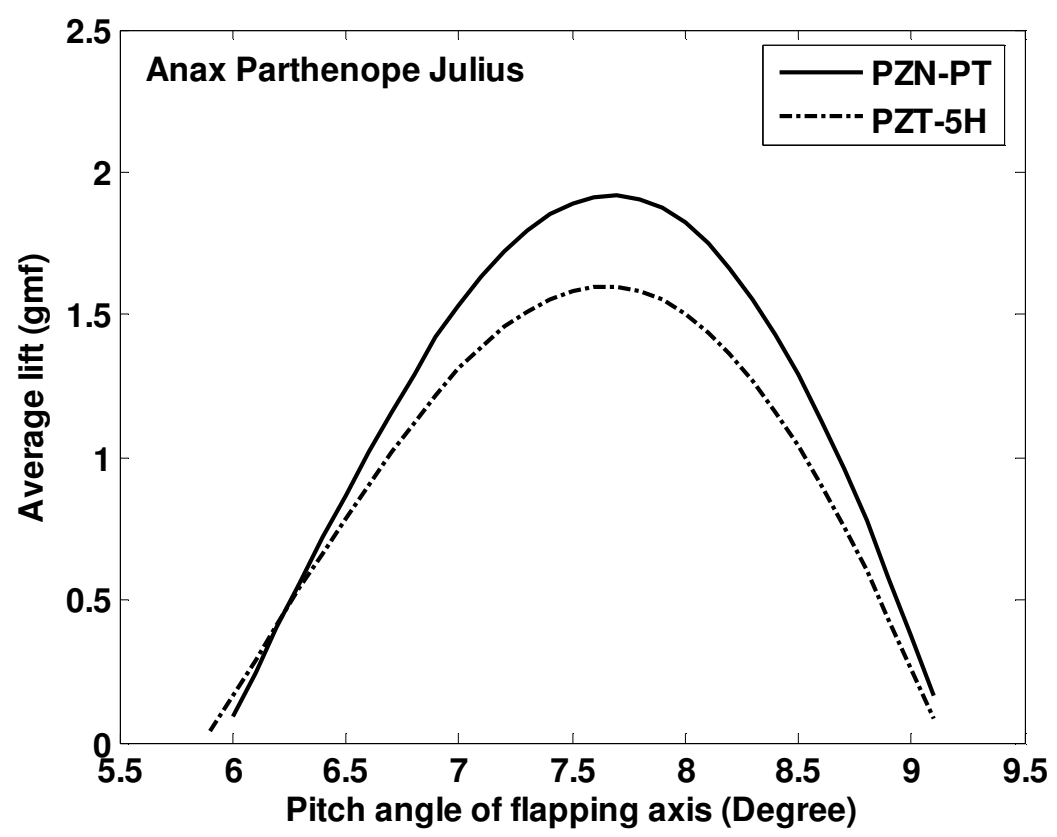

(b)

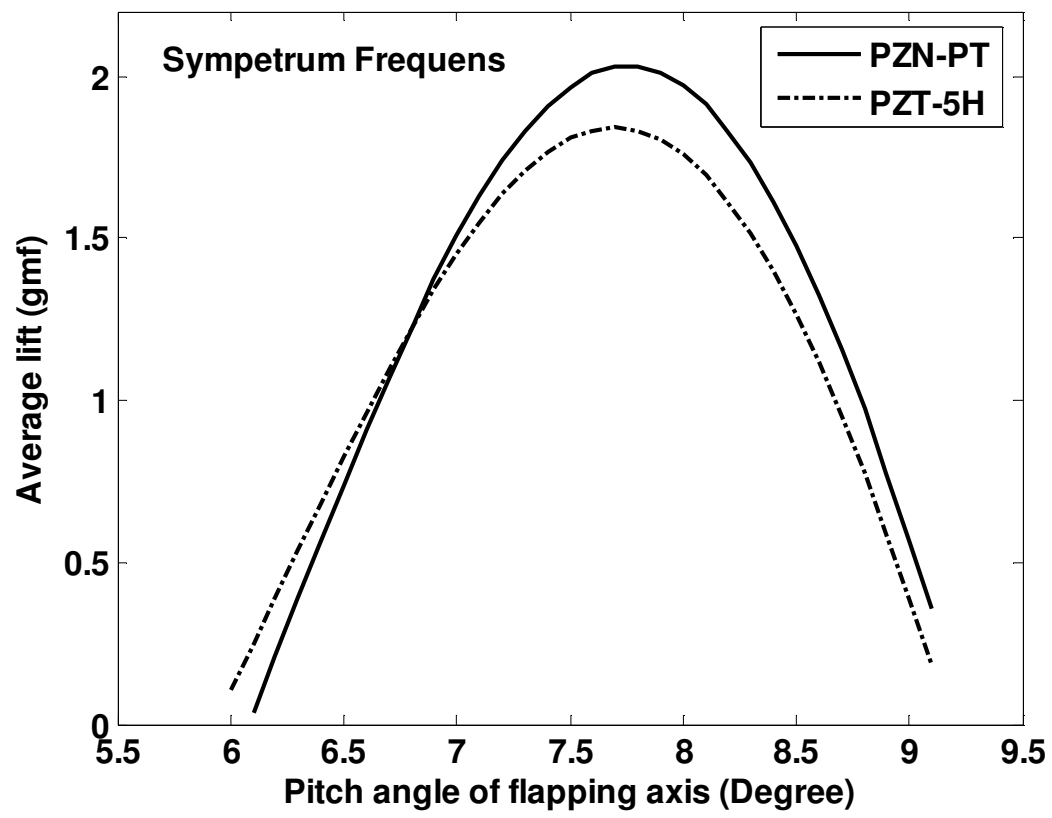

(c)

Fig. 14 Average lift of three dragonfly inspired smart flapping wings for different pitch angle 


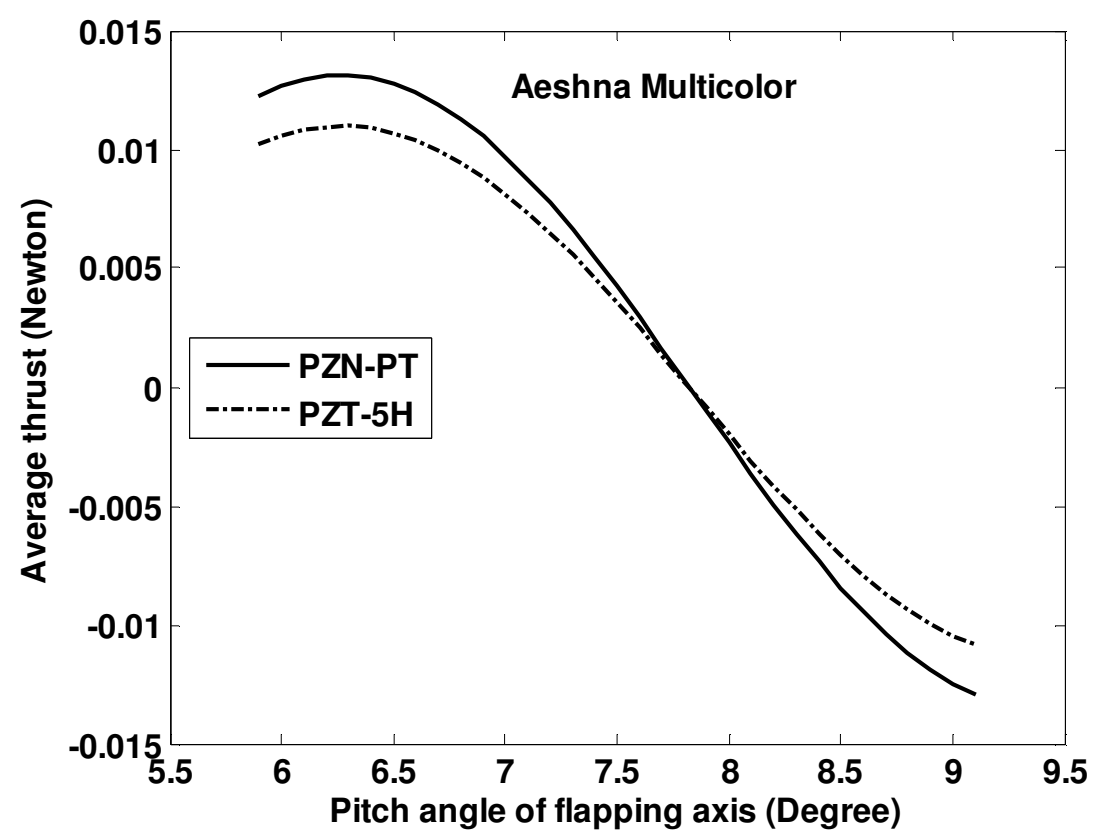

(a)

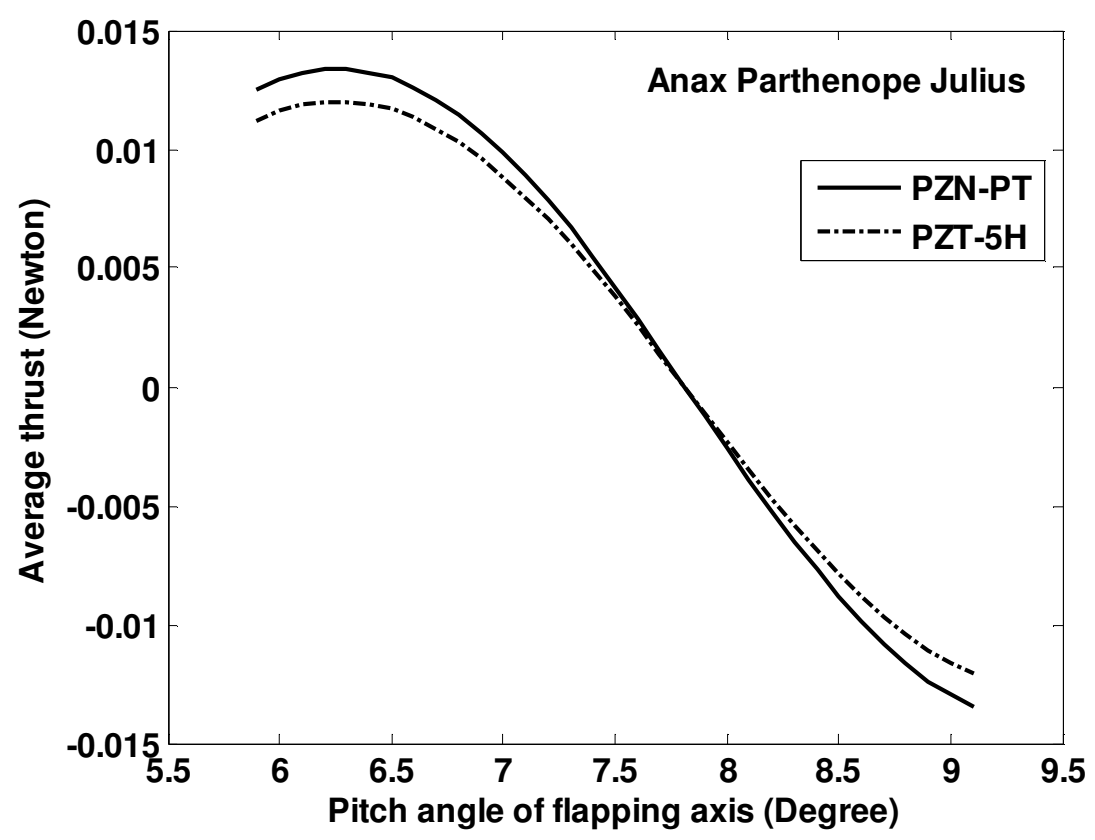

(b) 


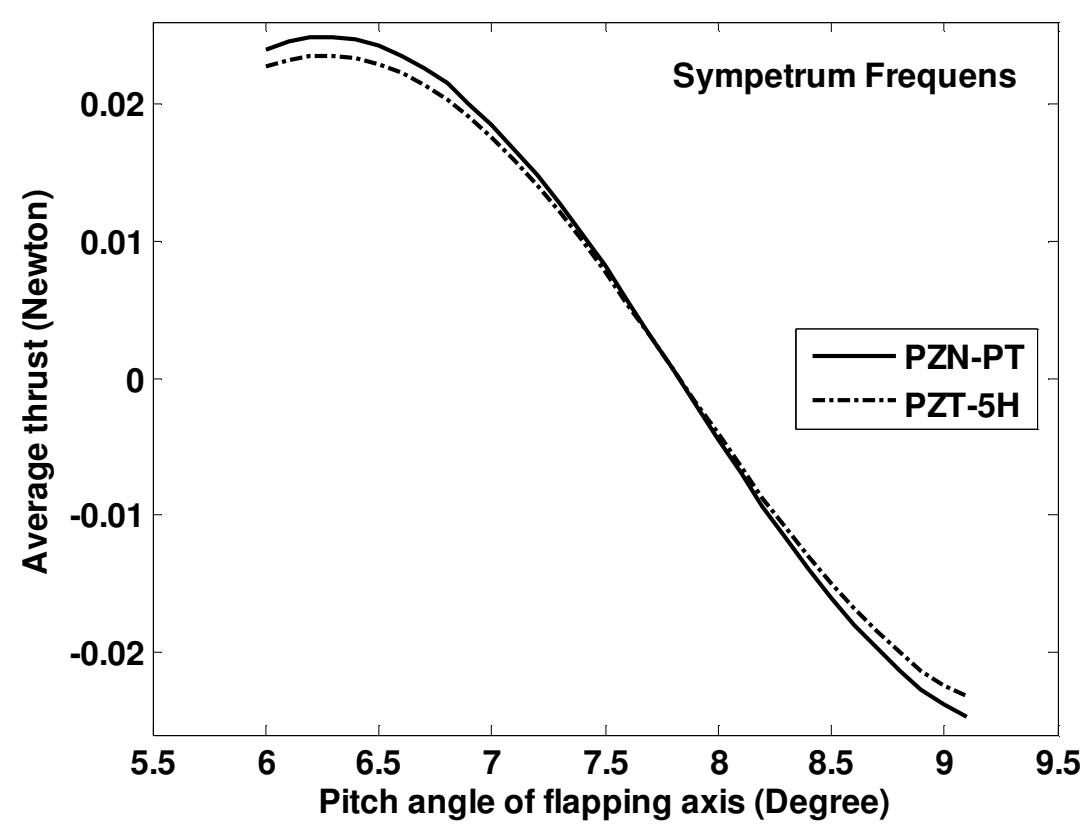

(c)

Fig. 15 Average thrust of three dragonfly inspired smart flapping wings for different pitch angle

\subsubsection{Aerodynamic forces at different flight speeds}

Fig. 16 shows the average lift produced by smart flapping wings at different flight speeds. In all these cases, a pitch angle of $7^{0}$ is used. It can be seen from the Fig. 16(a) that the maximum lift force for Aeshna Multicolor PZT-5H and PZN-7\%PT wing are $0.75 \mathrm{~g}$ and $0.79 \mathrm{~g}$ at the flight speed of $6.2 \mathrm{~m} / \mathrm{s}$ and $5.4 \mathrm{~m} / \mathrm{s}$, respectively. It can also be noted from Fig. 16(b) that the maximum lift force for Anax Parthenope Julius PZT-5H and PZN$7 \% \mathrm{PT}$ wing are $1.34 \mathrm{~g}$ and $1.46 \mathrm{~g}$ at the flight speed of $3.7 \mathrm{~m} / \mathrm{s}$ and $3.2 \mathrm{~m} / \mathrm{s}$, respectively. Fig 16(c) shows that the maximum lift force for Sympetrum Frequens PZT-5H and PZN$7 \% \mathrm{PT}$ wing are $1.55 \mathrm{~g}$ and $1.82 \mathrm{~g}$ at the flight speed of $2.1 \mathrm{~m} / \mathrm{s}$ and $1.9 \mathrm{~m} / \mathrm{s}$, respectively. 


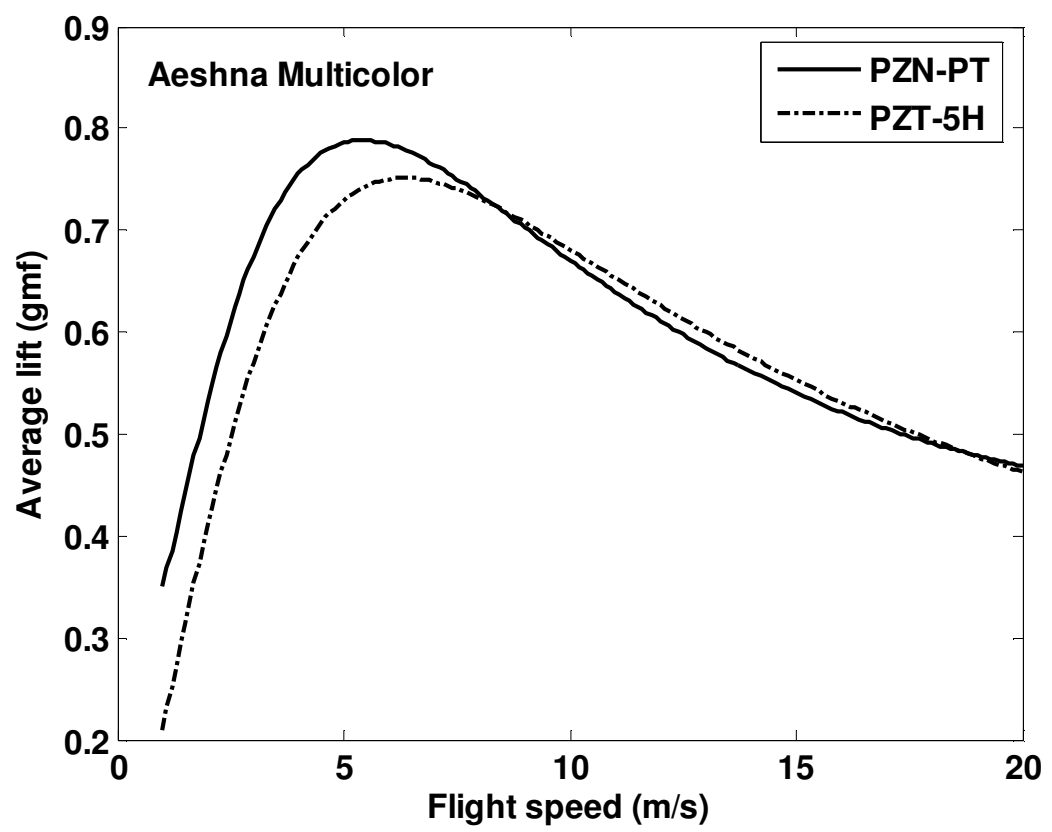

(a)

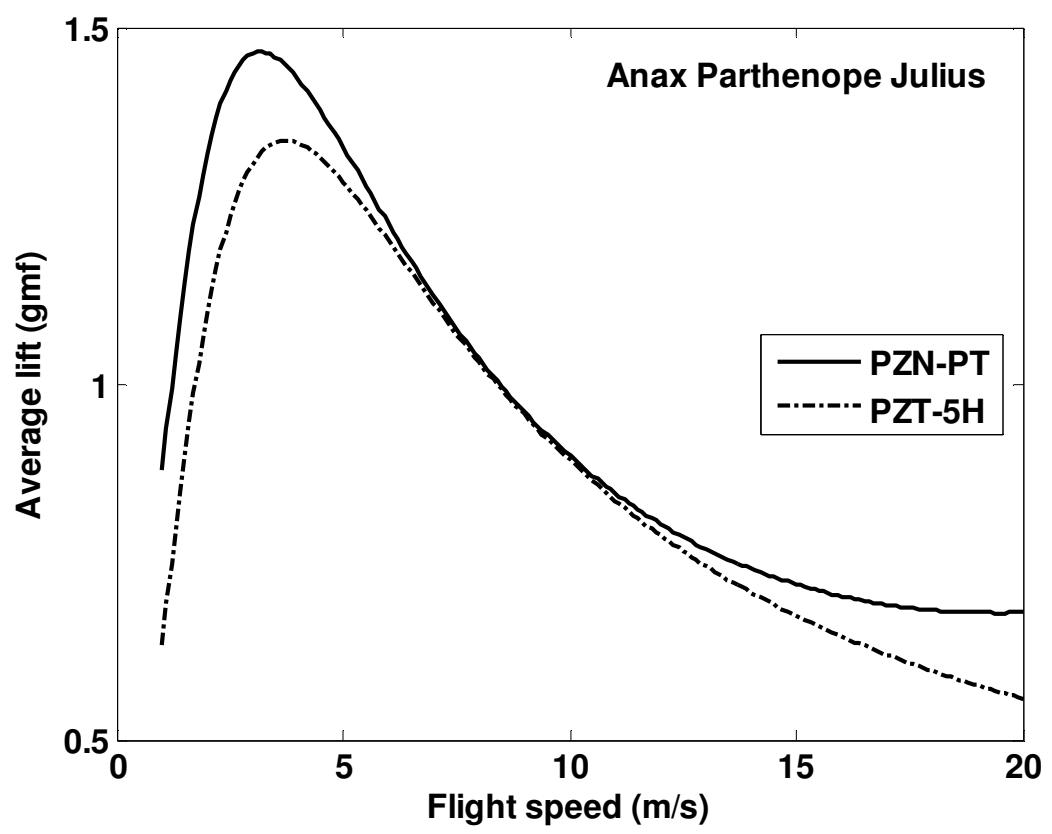

(b) 


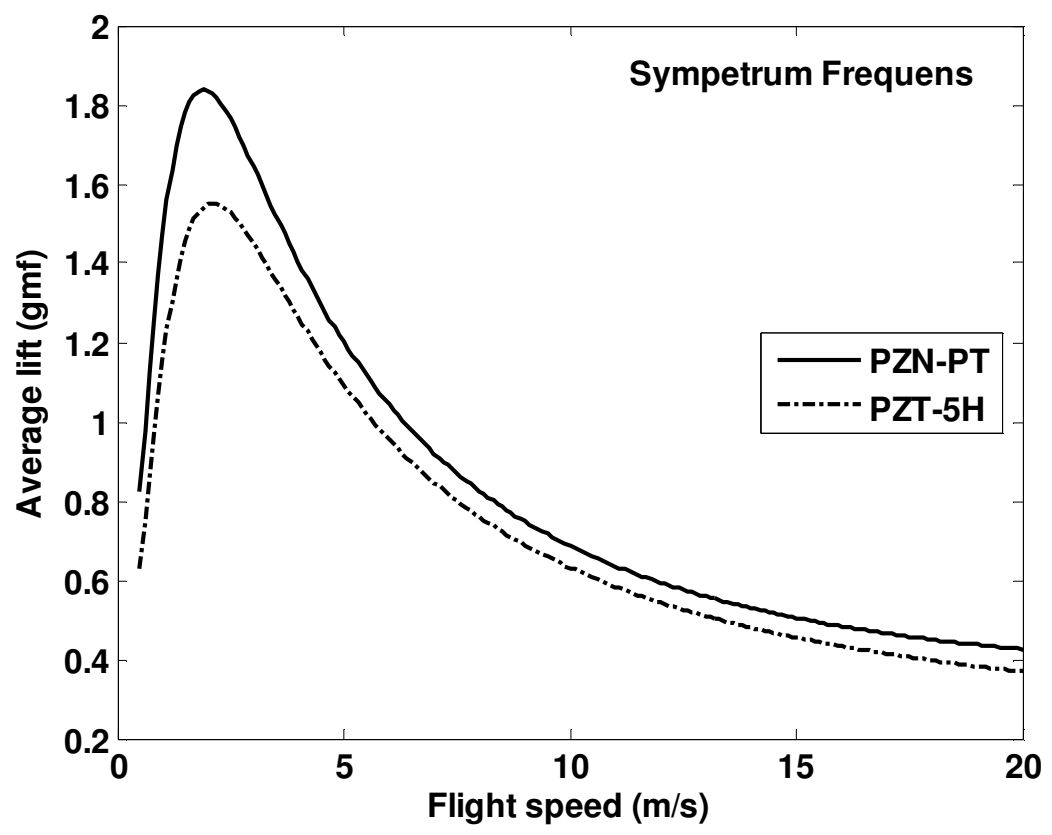

(c)

Fig. 16 Average lift of three dragonfly inspired smart flapping wings for different flight speed

Average thrust force at different flight speeds are shown in Fig. 17. It can be seen from Fig. 17(a) that the average thrust force for Aeshna Multicolor PZT-5H and PZN-7\%PT wing are found to be $0.0075 \mathrm{~N}$ and $0.0084 \mathrm{~N}$ at the flight speed of $6.2 \mathrm{~m} / \mathrm{s}$ and $5.4 \mathrm{~m} / \mathrm{s}$, respectively. Fig. 17(b) shows that the thrust force for Anax Parthenope Julius PZT-5H and PZN-7\%PT wing are $0.0066 \mathrm{~N}$ and $0.0069 \mathrm{~N}$ at the flight speed of $3.7 \mathrm{~m} / \mathrm{s}$ and 3.2 $\mathrm{m} / \mathrm{s}$, respectively. Similarly, thrust force for Sympetrum Frequens PZT-5H and PZN$7 \% \mathrm{PT}$ wing are found to be $0.01 \mathrm{~N}$ and $0.012 \mathrm{~N}$ at the flight speed of $2.1 \mathrm{~m} / \mathrm{s}$ and $1.9 \mathrm{~m} / \mathrm{s}$, respectively. 


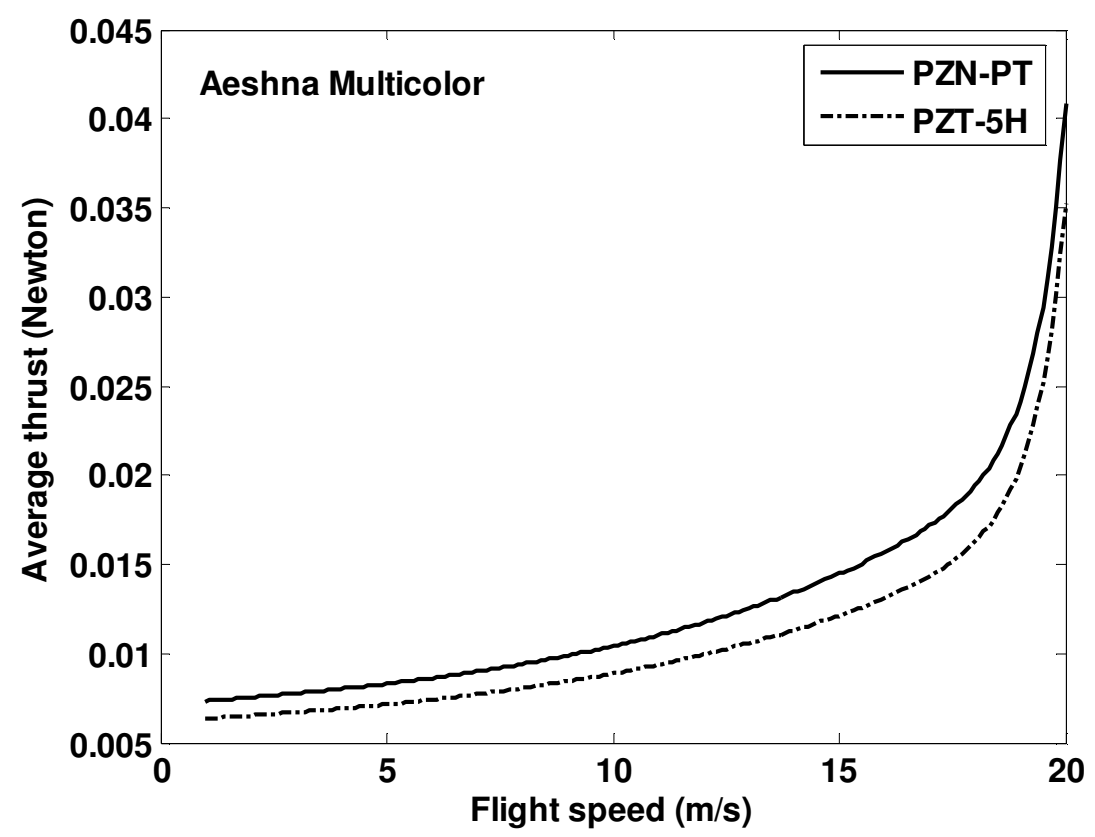

(a)

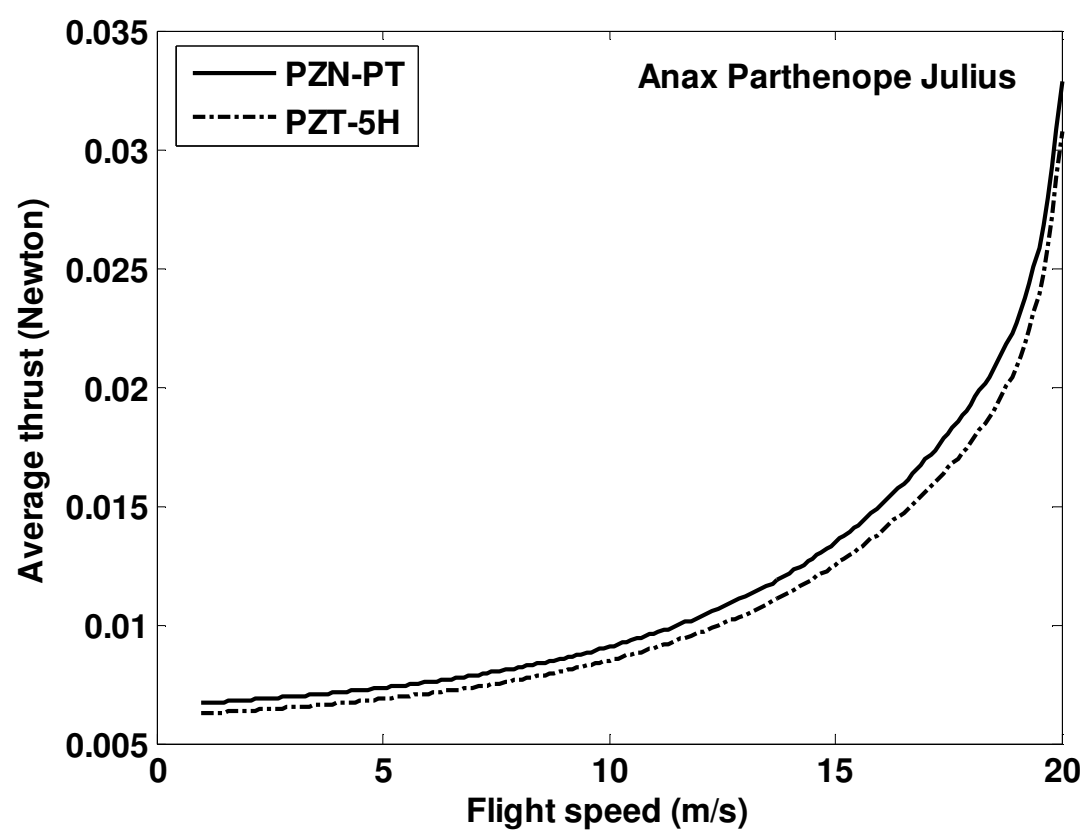

(b) 


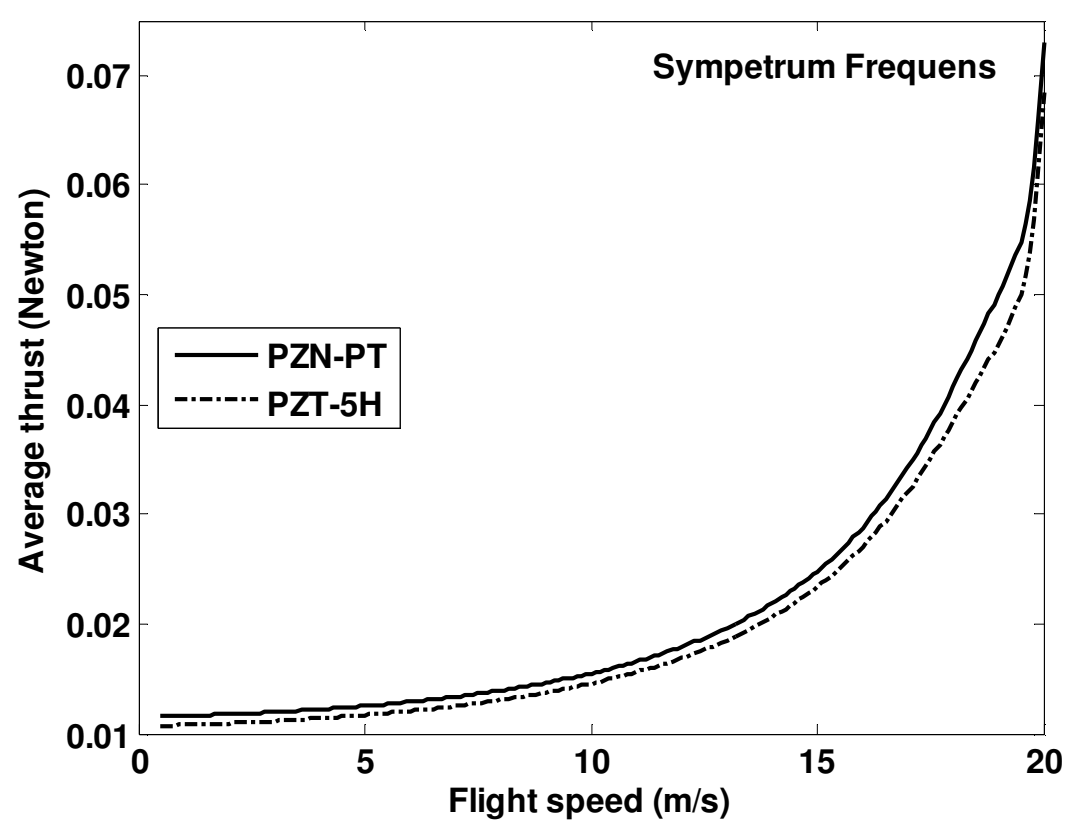

(c)

Fig. 17 Average thrust of three dragonfly inspired smart flapping wings for different flight speed

\subsubsection{Net lift forces}

Net lift force, obtained by subtracting the total wing weight from the total lift force, when two smart flapping wings are used for each species is shown in Fig. 18. It can be seen from Fig. 18(a) that the net lift produced by the Aeshna Multicolor PZT-5H wing is 0.99 $\mathrm{g}$ and it occurs at $6.2 \mathrm{~m} / \mathrm{s}$. Moreover, the net lift produced by the Aeshna Multicolor PZT$7 \% \mathrm{PT}$ wing at the flight speed of $5.4 \mathrm{~m} / \mathrm{s}$ is $1.14 \mathrm{~g}$ which is $15 \%$ more than that of PZT5H wing. Fig. 18(b) shows that net lift obtained for the Anax Parthenope Julius PZT-5H and PZT-7\%PT wing are $1.99 \mathrm{~g}$ and $2.33 \mathrm{~g}$ at a flight speed of $3.7 \mathrm{~m} / \mathrm{s}$ and $3.2 \mathrm{~m} / \mathrm{s}$, respectively. Therefore, the Anax Parthenope Julius PZT-7\%PT wing can produce 17\% more net lift compared to the PZT-5H wing. Similarly, net lift for Sympetrum Frequens PZT-5H and PZT-7\%PT wing reach up to $2.68 \mathrm{~g}$ and $3.27 \mathrm{~g}$ at the flight speed of $2.1 \mathrm{~m} / \mathrm{s}$ and $1.9 \mathrm{~m} / \mathrm{s}$, respectively, as shown in Fig. 18(c). Hence, Sympetrum Frequens PZT$7 \%$ PT wing can produce $22 \%$ more net lift than the corresponding PZT-5H wing. 


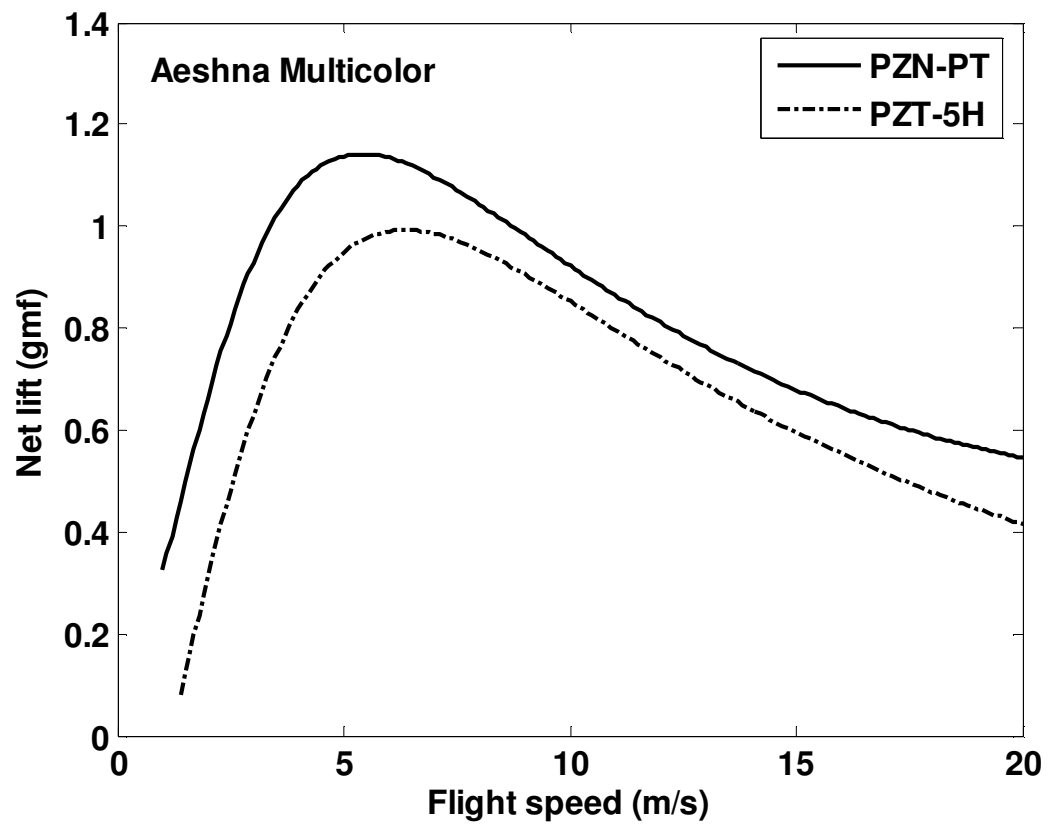

(a)

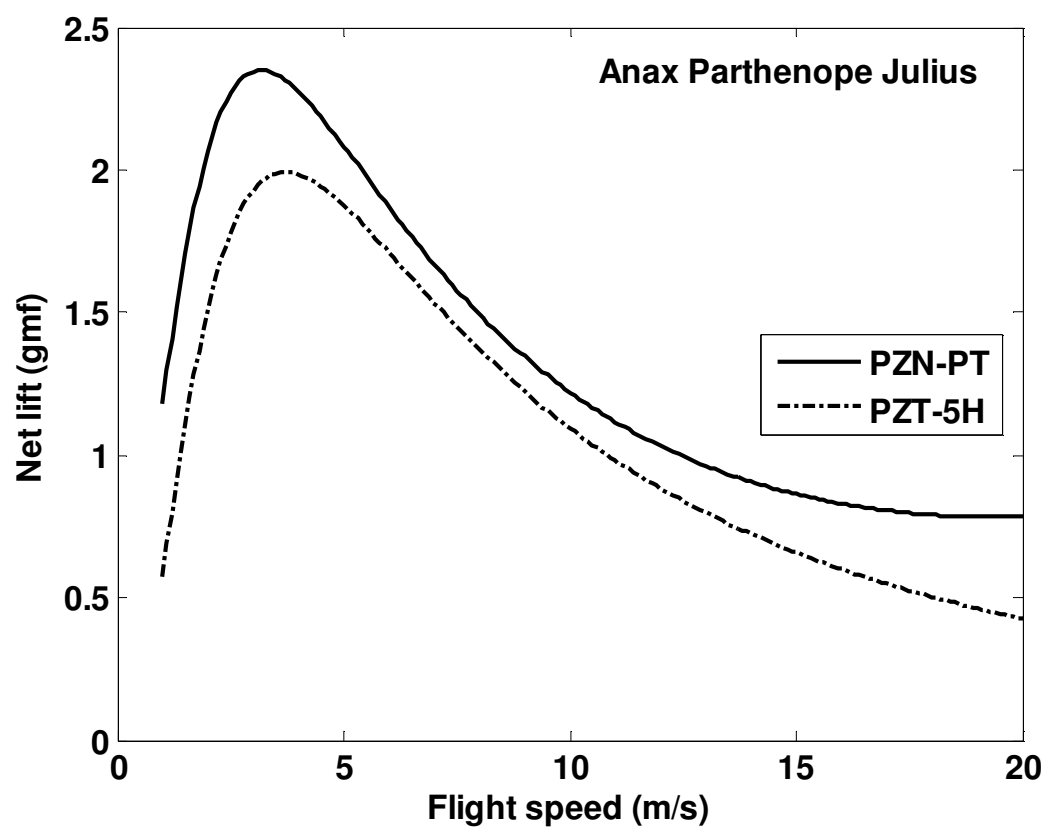

(b) 


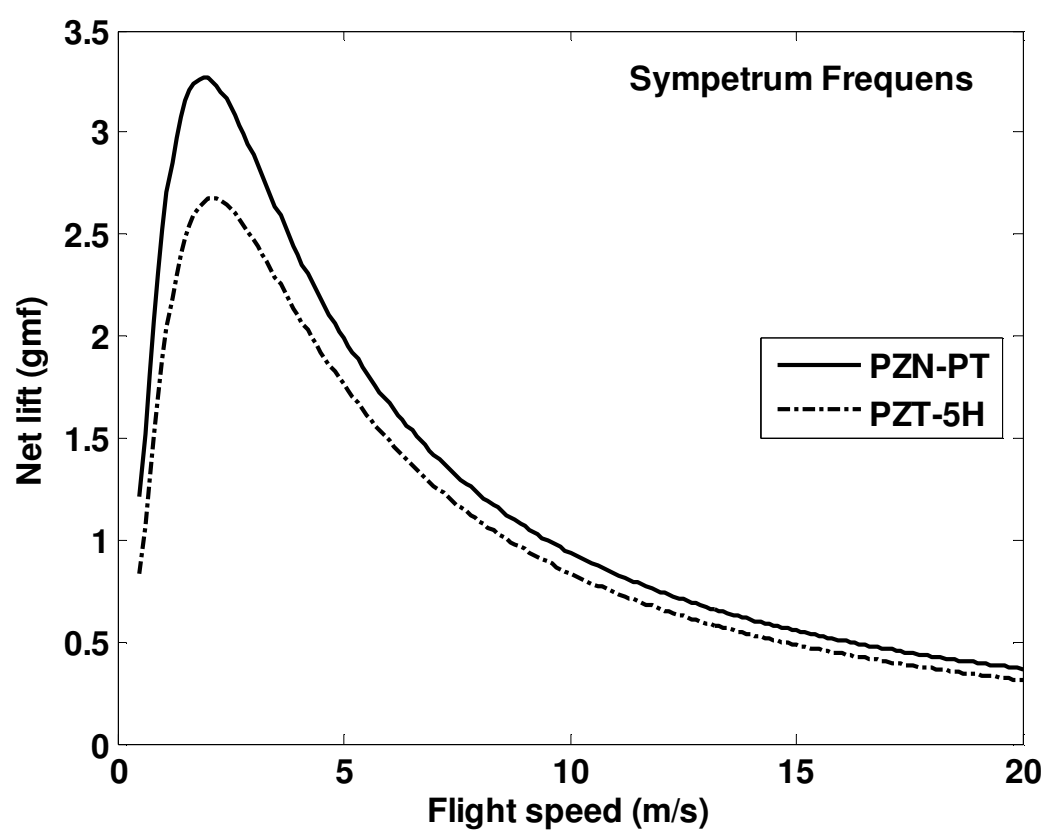

(c)

Fig. 18 Net lift of three dragonfly inspired smart flapping wings for different flight speeds

From the numerical results in the paper, it can be seen that the dynamic and aerodynamic performances of smart flapping wing based on the geometry of the dragonfly Sympetrum Frequens wing is best among the three boimimetic flapping wings. Use of PZN-7\%PT single crystal piezoceramic can lead to considerable amount of wing weight reduction and increase of lift and thrust force compared to PZT-5H material. Specifically, there is a wing weight reduction and an increase of net lift of $12 \%$ and $22 \%$, respectively, for Sympetrum Frequens PZT-7\%PT wing, compared to when PZT-5H is used. Therefore, biomimetic smart flapping wings based on the geometry of the dragonfly Sympetrum Frequens PZT-7\%PT wing represents an attractive design for insect scale flapping wing vehicles.

We would like to mention that the present study mainly focuses on the feasibility study of the flapping wing actuated by single crystal piezoceramic. There is a need for full aeroelastic consideration for more accurate prediction of aerodynamic forces as the forces produced by the flapping wing may change in the presence of aerodynamic loading. Moreover, the effects of the wing twist, due to aerodynamic loading, on the aerodynamic force generation need to be studied. These aspects of the problem have been taken up as a future work.

\section{Conclusions}

The Hamilton's principle is used in order to derive the non-linear equations of motion of a smart flapping wing. These equations are then discretized using the Galerkin method 
and solved using the method of multiple scales. Flapping wing is actuated from the root by a PZT-5H and PZN-7\%PT unimorph in the piezofan configuration. Dynamic characteristics of smart flapping wings, having the same size corresponding to the actual wings of three different dragonfly species, are analyzed using numerical simulations.

Dynamic characteristics of all the three different piezoelectrically actuated flapping wings are studied for an input excitation voltage of $60 \mathrm{~V}$. An unsteady aerodynamic model is used to obtain the aerodynamic forces. It is observed from the numerical results that net lift and thrust force produced by smart Sympetrum Frequens wing are highest among the three dragonfly inspired flapping wings considered in this study. Moreover, smart Sympetrum Frequens flapping wing is suitable for low speed flight. Use of PZN$7 \% \mathrm{PT}$ single crystal piezoceramic can lead to a weight reduction of $12 \%$ for smart Sympetrum Frequens flapping wing as compared to PZT-5H wing. At the same time, there is an increase of net lift of $22 \%$ for Sympetrum Frequens PZN-7\%PT wing as compared to PZT-5H wing. This net lift may be used to carry several sub-systems, such as power supply unit, control unit, sensory systems etc., required for autonomous flight. Therefore, PZN-7\%PT flapping wing based on geometry of dragonfly Sympetrum Frequens wing represents a potential candidate for use in insect scale micro air vehicles.

\section{References}

Ansari, S. A., Zbikowski, R. and Knowles, K. (2006) "Aerodynamic modelling of insectlike flapping flight for micro air vehicles," Progress in Aerospace Sciences, 42, 129-172.

Azuma, A., Azuma, S., Watanabe, I. and Furuta, T. (1985) "Flight mechanics of a dragonfly," Journal of Experimental Biology, 116(1), 79-107.

Bao, L., Hu, J. S., Yu, Y. L., Cheng, P., Xu, B. Q. and Tong, B. G. (2006) "Viscoelastic constitutive model related to deformation of insect wing under loading in flapping motion," Applied Mathematics and Mechanics, 27(6), 741-748.

Betteridge, D. S. and Archer, R. D. (1974) "A study of the mechanics of flapping wings," Aeronautical Quarterly, 25, 129-142.

Chandar, D. D. J. and Damodaran, M. (2010) "Computation of unsteady low Reynolds number free-flight aerodynamics of flapping wings," Journal of Aircraft, 47(1), 141-150.

Chopra, I. (2002) "Review of state of art of smart structures and integrated systems," AIAA Journal, 40(11), 2145-2187.

Chung, H. C., Kummari, K. L., Croucher, S. J., Lawson, N., Guo, S. and Huang, Z. (2008) "Coupled piezoelectric fans with two degree of freedom motion for the application of flapping wing micro aerial vehicles," Sensors and Actuators A - Physical, 147(2), 607-612. 
Chung, H. C., Kummari, K. L., Croucher, S. J., Lawson, N., Guo, S., Whatmore, R. W. and Huang, Z. (2009) "Development of piezoelectric fans for flapping wing application," Sensors and Actuators A - Physical, 149(1), 136-142.

Combes, S. A. and Daniel, T. L. (2003) "Flexural stiffness in insect wings II. Spatial distribution and dynamic wing bending," Journal of Experimental Biology, 206(17), 2989-2997.

Cox, A., Monopoli, D., Cveticanin, D., Goldfarb, M. and Garcia, E. (2002) "The development of elastodynamic components for piezoelectrically actuated flapping microair vehicles," Journal of Intelligent Material Systems and Structures, 13(9), 611-615.

DeLaurier, J. D. (1993) “An aerodynamic model for flapping-wing flight,” Aeronautical Journal, 97(964), 125-130.

Dickinson, M. H., Lehmann, F. O. and Sane, S. P. (1999) "Wing rotation and the aerodynamic basis of insect flight," Science, 284(5422), 1954-1960.

Ganguli, R., Gorb, S., Lehmann, F. O., Mukherjee, S. and Mukherjee, S. (2010) "An experimental and numerical study of Calliphora wing structure," Experimental Mechanics, 50(8), 1183-1197.

Hsieh, S. R., Shaw S. W. and Pierre, C. (1994) "Normal modes for large amplitude vibration of a cantilever beam," International Journal of Solids and Structures, 31(40), 1981-2014.

Issac, K. K and Agrawal, S. K. (2007) "An investigation into the use of springs and wing motions to minimize the power expended by a pigeon-sized mechanical bird for steady flight," Journal of Mechanical Design, 129(4), 381-389.

Ke, S., Zhigang, W. and Chao, Y. (2008) "Analysis and flexible structural modeling for oscillating wing utilizing aeroelasticity," Chinese Journal of Aeronautics, 21(5), 402-410.

Kim, D. K., Han, J. H. and Kwon, K. J. (2009) "Wind tunnel tests for a flapping wing model with a changeable camber using macro-fiber composite actuators," Smart Materials and Structures, 18(2), 024008.

Kim, D. K., Kim, H. I., Han, J. H., and Kwon, K. J. (2008) "Experimental investigation on the aerodynamic characteristics of a bio-mimetic flapping wing with macro-fiber composites," Journal of Intelligent Material Systems and Structures, 19(3), 423-431.

Kim, W. K., Ko, J. W., Park, H. C. and Byun, D. (2009) "Effects of corrugation of the dragonfly wing on gliding performance," Journal of Theoretical Biology, 260, 523-530.

Kim,D. K., Lee, J. S. and Han, J.-H. (2011) "Improved aerodynamic model for efficient analysis of flapping-wing flight," AIAA Journal, 49(4), 868-872. 
Lee, J. S., Kim, J. K., Kim, D. K. and Han, J. H. (2011) "Longitudinal flight dynamics of bio-inspired ornithopter considering fluid-structure interaction." AIAA Journal of Guidance, Control, and Dynamics, 34(3), 667-677.

Madangopal, R., Khan, Z. A. and Agrawal, S. K. (2005) "Biologically inspired design of small flapping wing air vehicles using four-bar mechanisms and quasi-steady aerodynamics," Journal of Mechanical Design, 127(4), 809-816.

Mahmoodi, S. N. and Jalili, N. (2007) "Non-linear vibrations and frequency response analysis of piezoelectrically driven microcantilevers," International Journal of NonLinear Mechanics, 42(4), 577-587.

McIntosh, S. H., Agrawal, S. K. and Khan, Z. (2006) "Design of a mechanism for biaxial rotation of a wing for a hovering vehicle," IEEE/ASME Transaction on Mechatronics, 11(2), 145-153.

Mukherjee, S. and Ganguli, R. (2010) "Non-linear dynamic analysis of a piezoelectrically actuated flapping wing," Journal of Intelligent Material Systems and Structures, 21(12), $1157-1167$.

Nayfeh, A. H. (1973) “Perturbation Methods," Wiley, New York.

Nayfeh, A. H. and Mook, D. T. (1979) “Nonlinear Oscillations," Wiley, NewYork.

Nguyen, V. Q., Syaifuddin, M., Park, H. C., Byun, D. Y., Goo, N. S. and Yoon, K. J. (2008) "Characteristics of an insect-mimicking flapping system actuated by a unimorph piezoceramic actuator," Journal of Intelligent Material Systems and Structures, 19(10), $1185-1193$.

Nguyen, V. Q., Park, H. C., Goo, N. S. and Byun, D. Y. (2010) "Characteristics of a Beetle's free flight and a flapping-wing system that mimics Beetle flight," Journal of Bionic Engineering, 7(1), 77-86.

Norberg, U. M. (1985) "Evolution of vertebrate flight: an aerodynamic model for the transient from gliding to active flight," The American Naturalist, 126(3), 303-327.

Pawar, P. M. and Jung, S. N. (2008) "Single-crystal-material-based induced-shear actuation for vibration reduction of helicopters with composite rotor system," Smart Materials \& Structures, 17(6), 065009: 1-11.

Philps, P. J., East, R. A. and Pratt, N. H. (1981) "An unsteady lifting-line theory of flapping wings with application to the forward flight of birds," Journal of Fluid Mechanics, 112(11), 97-125. 
Raney, D. L. and Slominski, E. C. (2004) "Mechanization and control concepts for biologically inspired micro aerial vehicles," Journal of Aircraft, 41(6), 1257-1265.

Rayner, J. M. V. (1979) "Vortex theory of animal flight. 2. Forward flight of birds," Journal of Fluid Mechanics, 91(4), 731-763.

Roget, B., Sitaraman, J., Harmon, R., Grauer, J., Hubbard, J. and Humbert, S. (2009) "Computational study of flexible wing ornithopter flight," Journal of Aircraft, 46(6), 2016-2031.

Rosenfeld, N. C. and Wereley, N. M. (2009) "Time-periodic stability of a flapping insect wing structure in hover," Journal of Aircraft, 46(2), 450-464.

Singh, B. and Chopra, I. (2008) "Insect-based hover-capable flapping wings for micro air vehicles: Experiments and analysis," AIAA Journal, 46(9), 2115-2135.

Sitti, M. (2003) "Piezoelectrically actuated four-bar mechanism with two flexible links for micromechanical flying insect thorax," IEEE-ASME Transactions on Mechatronics, 8(1), 26-36.

Sunada, S., Zeng, L. J. and Kawachi, K. (1998) "The relationship between dragonfly wing structure and torsional deformation," Journal of Theoretical Biology, 193(1), 39-45.

Syaifuddin, M., Park, H. C. and Goo, N. S. (2006) "Design and evaluation of a LIPCAactuated flapping device," Smart Materials and Structures, 15(5), 1225-1230.

Thakkar, D. and Ganguli, R. (2006a) "Single-crystal piezoceramic actuation for dynamic stall suppression," Sensors and Actuators A-Physical, 128(1), 151-157.

Thakkar, D. and Ganguli, R. (2006b) "Use of single crystal and soft piezoceramics for alleviation of flow separation induced vibration in a smart helicopter rotor," Smart Materials \& Structures, 15(2), 331-341.

Toda, M. and Osaka, S. (1979) "Vibrational fan using the piezoelectric polymer PVF2," Proceedings of the IEEE, 67(8), 1171-1173.

VandenBerg, C. and Ellington, C. P. (1997) "The vortex wake of a 'hovering' model hawkmoth," Philosophical Transactions of the Royal Society of London Series BBiological Sciences, 352(1351), 317-328.

Wait, S. M., Basak, S., Garimella, S. V. and Raman, A. (2007) "Piezoelectric fans using higher flexural modes for electronics cooling applications," IEEE Transactions on Components and Packaging Technologies, 30(1), 119-128.

Yamamoto, M. and Isogai, K. (2005) "Measurement of unsteady fluid dynamics forces for a mechanical dragonfly model," AIAA Journal, 43(12), 2475-2480. 
Yang, L. J., Hsu, C. K., Han, H. C. and Miao, J. M. (2009) "Light Flapping Micro Aerial Vehicle Using Electrical-Discharge Wire-Cutting Technique," Journal of Aircraft, 46(6), 1866-1874.

Yao, K. and Uchino, K. J. (2001) "Analysis on a composite cantilever beam coupling a piezoelectric bimorph to an elastic blade," Sensors and Actuators A - Physical, 89(3), 215-221.

Zehetner, C. and Irschik, H. (2008) "On the static and dynamic stability of beams with an axial piezoelectric actuation," Smart Structures and Systems, 4(1), 67-84.

Zeng, K., Pang, Y. S., Shen, L., Rajan, K. K. and Lim, L. C. (2008) "Elastic modulus, hardness and fracture behavior of $\mathrm{Pb}\left(\mathrm{Zn}_{1 / 3} \mathrm{Nb}_{2 / 3}\right) \mathrm{O}_{3}-\mathrm{PbTiO}_{3}$ single crystal," Materials Science and Engineering A, 472(1-2), 35-42.

Zhang, J. and Lu, X. Y. (2009) "Aerodynamic performance due to forewing and hindwing interaction in gliding dragonfly flight," Physical Review E, 80(1), 017302-4.

Zhang, R., Jiang, B. and Cao, W. (2002) "Complete set of material constants of $0.93 \mathrm{~Pb}\left(\mathrm{Zn}_{1 / 3} \mathrm{Nb}_{2 / 3}\right) \mathrm{O}_{3}-0.07 \mathrm{PbTiO}_{3}$ domain engineered single crystal," Journal of Materials Science Letters, 21(23), 1877-1879.

\section{Notation}

$\begin{array}{lll}b & : & \text { Wing width } \\ c & : & \text { Airfoil chord } \\ c_{n} & : & \text { Normal force coefficient } \\ \left(C_{d}\right)_{f} & : & \text { Drag coefficient due to skin friction } \\ D & : & \text { Electrical displacement vector } \\ E_{b} & : & \text { Wing modulus of elasticity } \\ E_{p} & : & \text { Piezoelectric modulus of elasticity } \\ f(t) & : & \text { Harmonic excitation voltage } \\ h & : & \text { Coupling co-efficient matrix } \\ l & : & \text { Wing length } \\ l_{2}-l_{l} & : & \text { Piezoelectric layer length }\end{array}$




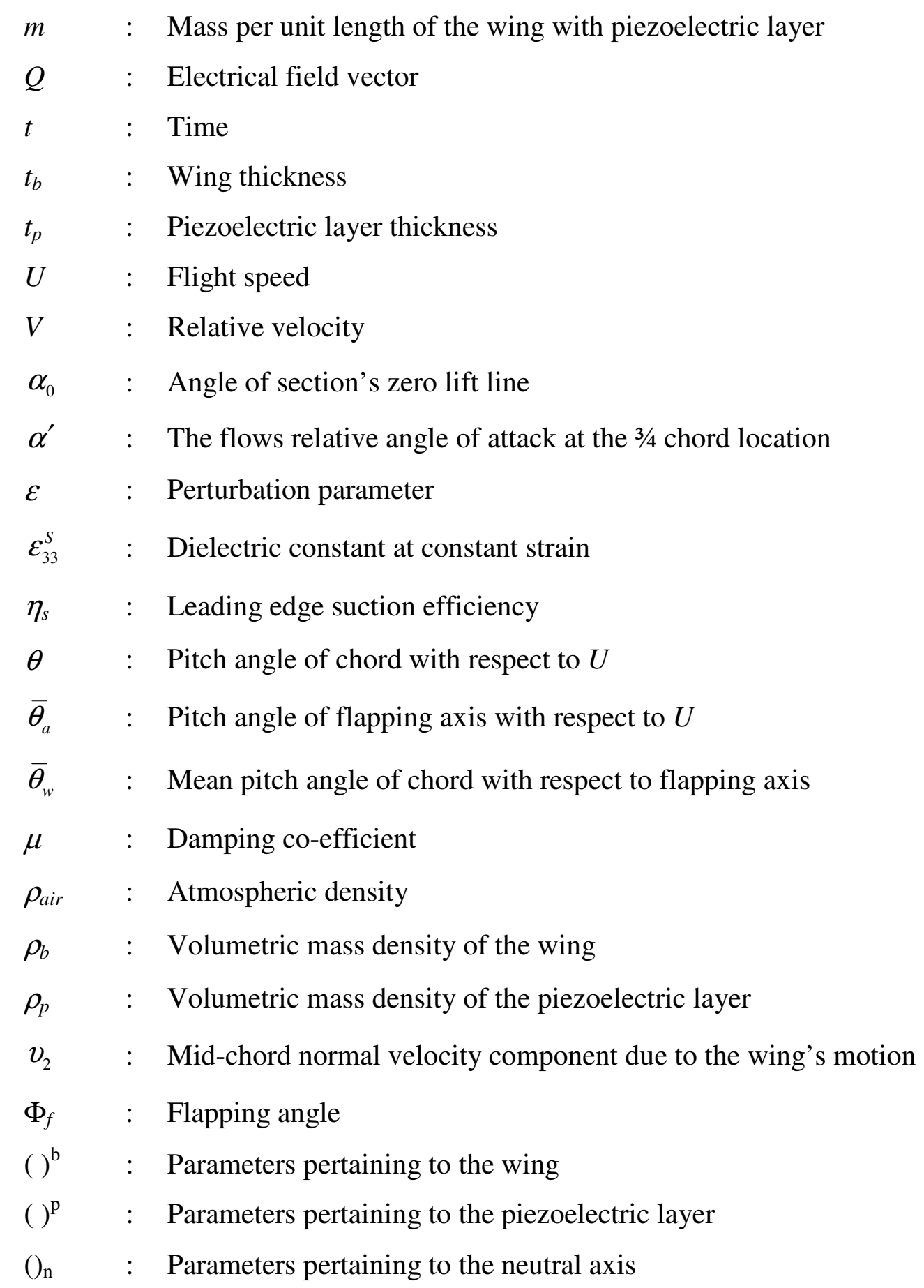

